\title{
Radioisotope scanning of brain, liver, lung and bone with a note on tumour localizing agents
}

\author{
J. P. LAVENDER \\ F.R.C.P.(Ed.), M.R.C.P., F.F.R. \\ Department of Radiodiagnosis, Hammersmith Hospital and Royal Postgraduate Medical School, \\ Ducane Road, London, W.12
}

\section{Summary}

Radioisotopic scanning of brain, liver, lungs and the skeleton is briefly reviewed with a survey of recent developments of clinical significance. In brain scanning neoplasm detection rates of greater than $90 \%$ are claimed. The true figure is probably $\mathbf{7 0 - 8 0} \%$. Autopsy data shows a number of false negatives, particularly with vascular lesions. Attempts to make scanning more specific in differentiating neoplasm from vascular lesions by rapid sequence blood flow studies are reviewed.

In liver scanning by means of colloids again high success rate is claimed but small metastases are frequently missed and the false negative scan rate is probably quite high.

Lung scanning still has its main place in investigating pulmonary embolic disease. Ventilation studies using Xenon 133 are useful, particularly combined with perfusion studies.

The various radiopharmaceuticals for use in bone scanning are reviewed. The appearance of technetium labelled phosphate compounds will probably allow much wider use of total skeletal scanning.

Research into tumour localizing agents continues, the most recent and interesting being Gallium citrate and labelled bleomycin. Neither agent is predictable however although Gallium may have a place in Hodgkins disease and bronchogenic neoplasm and both may have a place in the detection of cerebral tumours.

\section{Introduction}

This brief review is intended to look at some of the more common applications of radioisotope scanning, and also at certain new developments, in their clinical setting. Recent changes in detecting apparatus and in radiopharmaceuticals are widening the scope of scanning procedures, making investigations more specific; this outline may indicate the type of information and the order of accuracy that can be expected from the various investigations covered.

\section{Brain scanning}

Brain scanning is the most fruitful application of radioisotope scanning. It achieves this position partly from its accuracy and simplicity, partly because of the problems posed by other means of $\overrightarrow{0}$ investigating the brain. It has been shown that the plain skull radiograph rarely provides new informa- $\vec{\omega}$ tion when used as a screening test in, for instance, the detection of occult tumours in late onset epilepsy (Bull \& Zirkha, 1968). Angiography or pneumoencephalography, however, carry too high a mor- 6 bidity to be undertaken lightly or without fairly definite indications. Brain scanning, therefore, which has few false positives, an accuracy of about $75 \%$ for $\vec{\infty}$ brain tumours, with no morbidity or mortality, $ᄋ$ performs a very good screening test in this situation.

The usefulness of brain scanning, however, is not $c$ limited to its role as a screening test. It can also be applied to the patient with a neurological deficit $\vec{\theta}$ undergoing investigation and will often in these $\omega$ circumstances give added information additional that provided by arteriography. Accurate localiza: tion of neoplasms, for example, prior to surgery maty sometimes be more easily made on the scan than the $\bar{\partial}$ angiogram, especially for mid-line tumours. Perhaps of greater help is the situation of a patient with $\stackrel{\mathbb{Q}}{2}$ multiple lesions, due for instance to metastatic $\overrightarrow{\vec{O}}$ deposits; a situation usually readily diagnosed on 3 the brain scan but often less easily visible on the arteriogram.

The distinction between brain tumours and vascu- $\frac{\partial}{\partial}$ lar lesions is often still impossible, but with recent $\underline{3}$. advances in techniques the brain scan is becoming more and more specific. Some indication of cerebral blood flow can be obtained by sequential scanning 0 and again, by rapid sequential pictures, an indication of the patency of major extra-cranial vessels can 음 be obtained.

For a technique of such wide and proven usefulness there is marked under-utilization in this country. $N$ Calculation based on a DHSS report relating to 1970 shows that at that time about sixty brain scans 0 were performed daily for the whole of England and $\tilde{\omega}$ Wales. In relation to the number of patients undergoing neurological investigations each day this seems a very small figure indeed.

\section{Technique and radiopharmaceuticals}

The concept of brain scanning and early techniques were pioneered by Moore (1948) who utilized 
a hand-held Geiger-Muller counter to detect iodinelabelled fluorescein and later, iodine-labelled human serum albumin. Mercury-labelled neohydrin was introduced by Blau \& Bender in 1959 and in 1964 Harper et al., introduced ${ }^{99 \mathrm{~m}}$ technetium. This agent, because of its convenience and favourable physical characteristics is now the most widely used agent. Chelates of ${ }^{113} \mathrm{~m}$ indium are also in use, but offer no advantage over technetium. Coincident with these advances in radiopharmaceuticals there has been a vast improvement in apparatus for detection and display of radioactivity. This has taken the form of the evolving linear scanner, now usually with twin opposed heads which scan the patient and print out a static picture on film or paper. The alternative and probably more widely used instrument for brain scanning is a gamma camera; a single large detector which can be used either to build up a static picture or can record dynamic events such as the changing distribution of a bolus of radioactivity as it passes through a vascular bed. Tomographic cameras and scanners are now coming into use and the advantages of such instruments have been beautifully demonstrated by Kuhl \& Sanders (1971). Considerable efforts have gone into 'data processing' of scans, either in the form of the analysis of time activity curves or the recording and subsequent manipulation of static pictures. It seems doubtful at the time of writing whether these procedures add more than marginally to the accuracy of scanning, but for a review of this subject see Popham (1972).

\section{The normal brain scan}

Radiopharmaceuticals used for brain scanning are based on the fact that normal brain tissue is relatively impermeable, i.e. the radioactivity remains within the intravascular bed. Many lesions of the brain result in an increased permeability of this vascular bed resulting in a leakage of radio-activity into the lesion. As the radiopharmaceutical is excreted and blood cleared this area of leakage is increasingly apparent against the very low radioactivity of the surrounding brain. Large 'blood pools' such as venous sinuses are seen because of residual radioactivity and it is evident from this description that other abnormal blood pools such as aneurysms and arteriovenous malformations will also appear. It will also be apparent that the change in blood/brain barrier is non-specific. However, some indication of the pathology may be obtained as outlined in ensuing sections.

In performing a brain scan with technetium the patient should be premedicated by potassium perchlorate by mouth some $2 \mathrm{hr}$ before the examination, to prevent uptake in thyroid, salivary glands, choroid plexus and gastro-intestinal mucosa. Normally $10 \mathrm{mCi}{ }^{99} \mathrm{~m} \mathrm{Tc}$ as pertechnetate is injected intra- venously and at least four views (both laterals, a frontal and a posterior view obtained at $60 \mathrm{~min}$, each view containing at least 200,000 scintillations. If a gamma camera is used, this can be supplemented by additional views, such as the vertex view and views of the posterior fossa. A further advantage of the use of the gamma camera is its use in recording 'dynamic' events. A series of rapid exposures using an automatic camera will record the passage of a bolus of radioactivity through the arterial and venous phases of the cerebral circulation. This method can be used to visualize the major extracranial vessels.

The normal brain scan (Fig. 1) shows a 'halo' of radioactivity due to the scalp and soft tissues, and superimposed on this the venous sinuses are visible. The tongue, paranasal sinuses and mucosa of the nasopharynx all show relatively high levels of radioactivity. The posterior fossa can normally be seen quite readily, but overlying soft tissues cause a higher count rate, which tend to obscure pathology.

\section{Brain tumours}

Apart from acoustic neuromas (Baum \& Rothballer, 1972), which appear to take up pertechnetate, most brain tumours show lower levels of activity when compared to blood. Normal brain, however, has a very low level of radioactivity and therefore a ratio between 10 and 20:1 of tumour to brain can be achieved (Schwartz \& Tator, 1972). The diagnostic accuracy for supratentorial brain tumours is approximately $75 \%$ (Bucy \& Ciric, 1965; McAfee et al., 1964), although in some series detection rates of $90 \%$ are claimed (Kuba, Klaus \& Sevcik, 1971). The success rates undoubtedly vary with differing types and location of tumours. $90 \%$ or more of meningiomas are detected in most series and a high proportion of glioblastomas, whereas low grade astrocytomas and benign lesions, such as epidermoids, may show negative scans. Thus in a recently reported series (Naoun et al., 1971) reviewing 1100 scans using technetium, thirty meningiomas were all successfully detected and fifty-eight out of fifty-nine grade 3 and 4 astrocytomas. (Examples of both primary and metastatic tumours are illustrated in Figs. 2 and 3.)

Most workers involved in day-to-day scanning would agree to the difficulty of detecting a high proportion of lesions of the posterior fossa. If such a lesion is suspected, however, and particular attention is paid to its detection success rate may no doubt be higher, and this may explain the relatively good figures which appear in published work. Moody et al. (1972) for example, claim $78 \%$ success in a series of thirty-seven patients.

Figures quoted from the various series above are taken from patients assessed clinically or coming to surgery. A less rosy picture is presented if the figures 

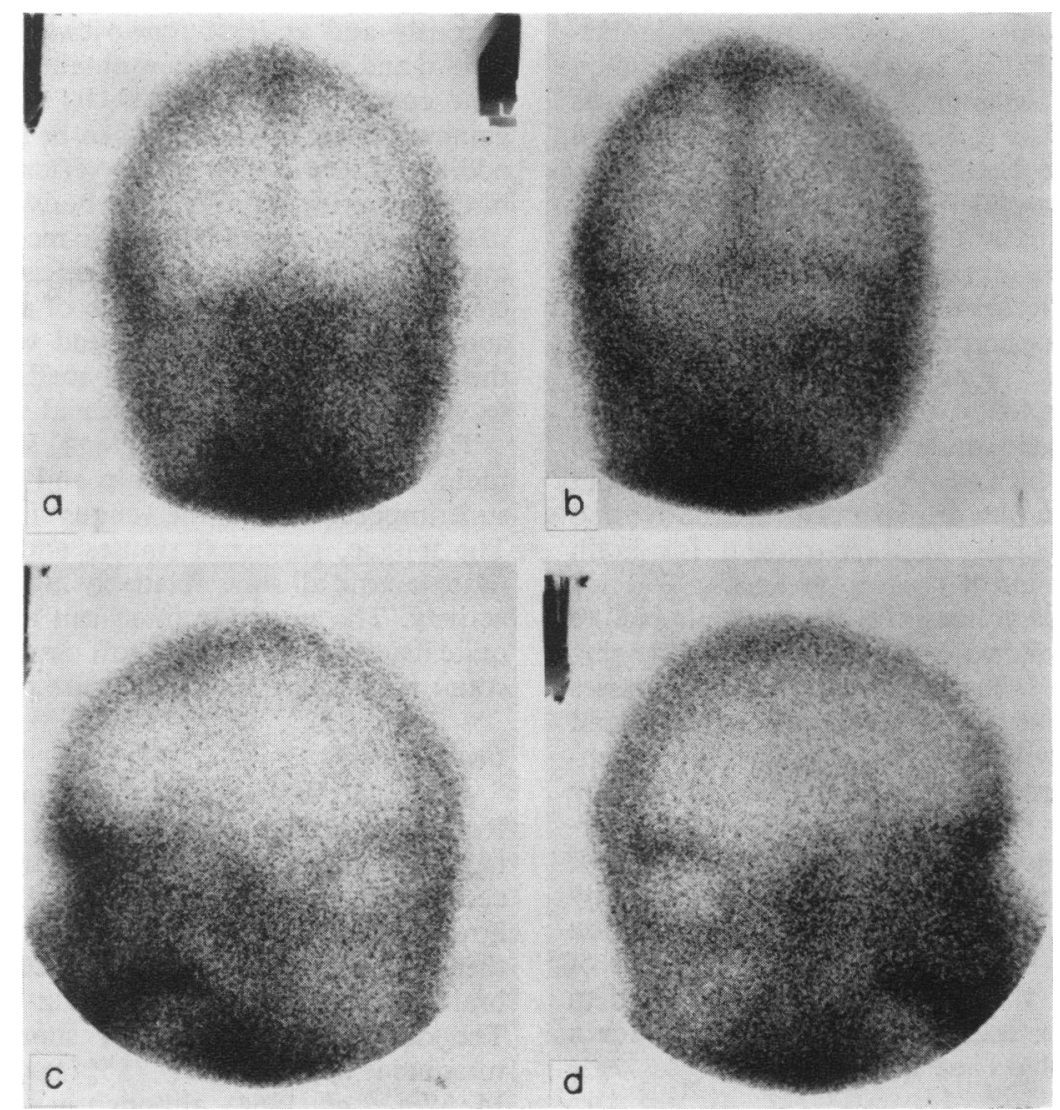

FIG. 1. Normal brain scan (gamma camera). (a) Anterior; (b) posterior; (c) and (d) left and right laterals.

In the frontal views there is a halo of radioactivity due to the scalp and soft tissues, the saggital sinus lies in the mid line with symmetrical areas of low count rates over the cerebral hemispheres on both sides. The lateral and sigmoid sinuses are seen on the posterior and lateral views, the area below representing posterior fossa. Note the high level of radioactivity in the face and nasopharynx.

are obtained from necropsy data. Thus Krishnamurthy et al. (1972) examined data on eighty-four patients who had had a brain scan within 6 weeks of death. The total success rate was $66 \%$ correct. There was only one false positive, but thirty-three patients had lesions shown at necropsy who had previously had a negative brain scan. The majority of these were vascular lesions, but five metastatic tumours and two primary tumours were missed, one an acoustic neuroma and one a 'lymphosarcoma'.

\section{Vascular lesions of the brain}

As mentioned in the section on the normal brain scan, large aneurysms and arteriovenous malformations may be visible on the scan, especially using 'early' pictures, but these will not be considered further. Three other types of vascular lesions of the brain, namely brain infarcts including intracerebra․ haematomas, subdural haemotomas and majob lesions of the extracranial vessels, can all be diagnose with varying degrees of accuracy by brain scanningo

Infarction of the brain may cause an abnorma brain scan (Fig. 5). The scan characteristically has poorly delineated margins fading off into the norma brain tissue and frequently covers a relatively large area of brain. The proportion of patients showing this abnormality on the scan varies in different serie that have been followed (Morrison et al., 1965 Glasgow, Currier \& Goodrich, 1967). In general it is about $50 \%$. It is evident, however, that this depend $\$$ on the time at which the scan is performed in relation? to the onset of illness. During the first week less thano $25 \%$ of patients may show a positive scan and prob. ably more than $50 \%$ will be positive at some time 

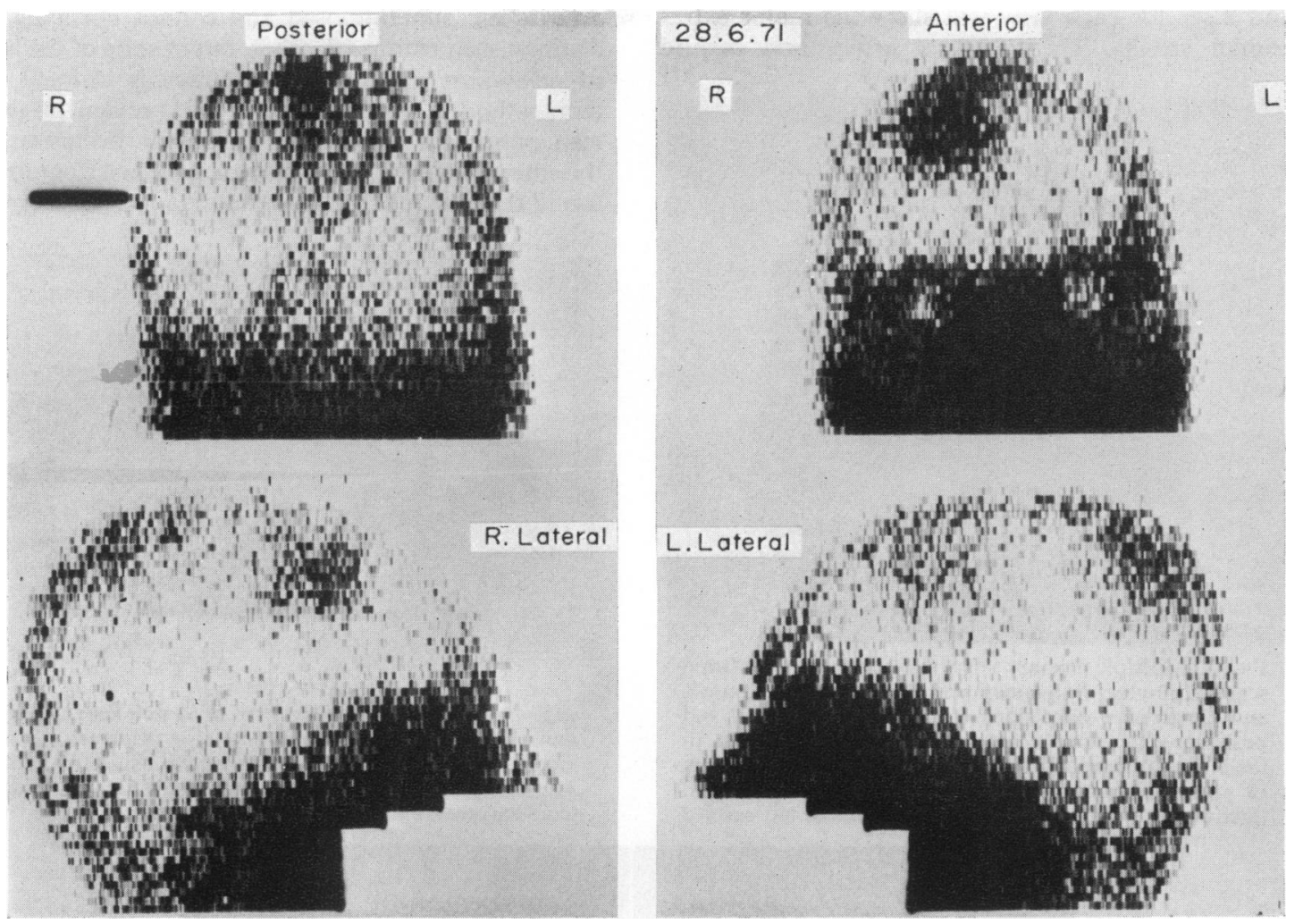

FIG. 2. Brain scan in metastases from bronchial carcinoma. Brain scan on a 51-year-old man who presented with a monoparesis of his right leg of 1 week's duration. Chest X-ray showed a mass in the right upper lobe. The brain scan shows two areas of increased activity, one in the right frontoparietal region seen on the anterior and right lateral view (appearing more diffusely also on the left lateral) and a second lesion in the left posterior parietal region seen on the left lateral and posterior views. These lesions were confirmed at necropsy at which time other smaller metastases were also seen.

during the first 2-3 weeks (Molinari, Percher \& Hayman, 1967). How can the appearances of the abnormal brain scan be differentiated from those of neoplasm? As mentioned above the scan often has a fairly characteristic appearance but this is by no means specific. Repeated scans over a period of weeks will usually show a changing pattern. A number of centres are now using rapid sequence pictures during the passage of a bolus of radioactivity through cerebral vessels, and by this means a series of images is obtained representing transit and, therefore, cerebral blood flow. Using this technique Moses et al. (1972) examined sixty-eight patients with acute strokes and found abnormalities present on the rapid sequence scans in $57 \%$, only $32 \%$ having abnormal scans performed in a conventional way. By this means one can detect areas of poor or delayed perfusion and attempt to differentiate between an abnormal brain scan due to a vascular lesion from that due to a neoplasm. The vascular lesion charac- teristically will show an area of diminished perfusion during the arterial phase of the rapid sequence views and may show increased activity during the late venous phase, or may remain an area of low activity during the whole of the rapid sequence pictures (Fig. 5). In contrast, a vascular tumour will be seen as an area of increased activity during the arterial pictures and this is the characteristic appearance in meningiomas and vascular gliomas (Fig. 6). A development or refinement of this technique is to plot time activity curves over different regions of the brain, where again characteristic patterns are described in infarcts, vascular tumours and relatively slow growing nonvascular tumours (Rosenthall, 1971).

A further application of the technique of rapid sequential pictures following a bolus of radioactivity is that of visualizing major extra-cranial vessels. For this purpose the gamma camera is centred over the neck and base of the skull, either posteriorly or anteriorly, and a series of views lasting between 1 
and $2 \mathrm{sec}$ for each view will show the major extracranial vessels. The vertebral artery and carotid

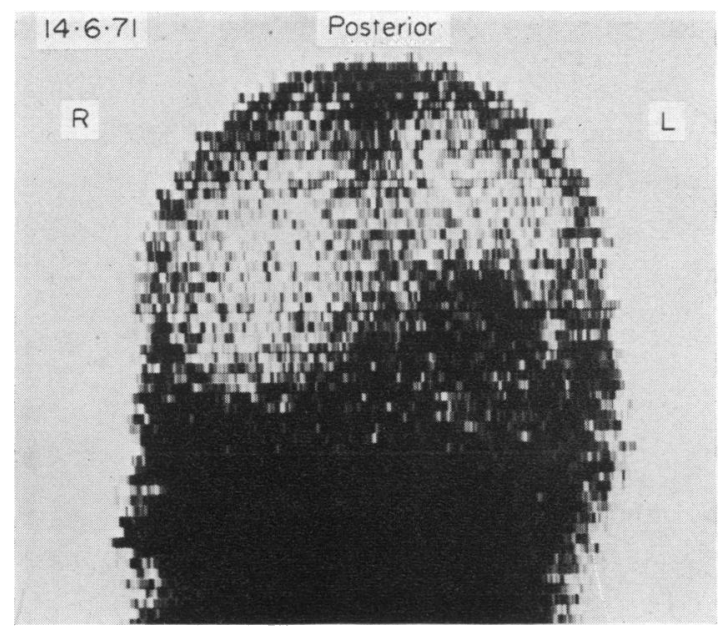

FIG. 3. Multiple primary intracranial tumours. (a) Brain scan on 40-year-old woman presenting with hemianopia and progressive right sided weakness. Both lateral and posterior views show a large area of increased activity in the posterior temporal and occipital areas. A further area of increased activity is seen in the frontal region (arrowed). (b) Arterial and venous phases of left carotid

arteries are superimposed and cannot normally b气̊ distinguished from each other, but in spite of the lack of resolution considerable accuracy is claimed fo尺 this method. Thus Wise et al. (1971) reviewing thir $\stackrel{C}{-}$ teen patients with severe stenoses or occlusion of the internal carotid demonstrated by arteriography found that the radionuclide examination was corrects

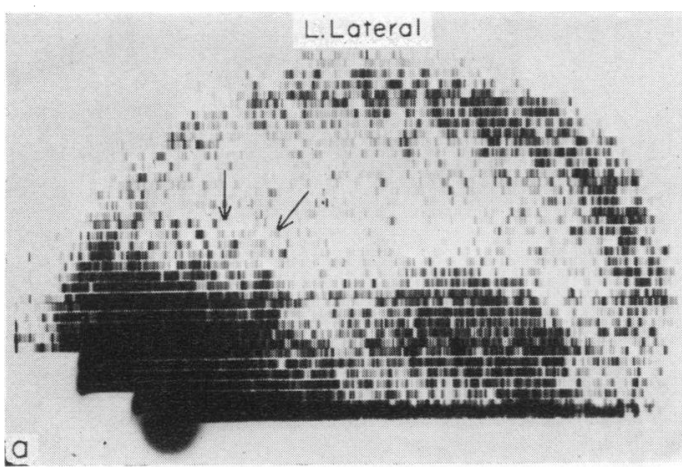

angiogram showing displacement of vessels due to large mass in left occipital region and also displacement of $c$ anterior cerebral artery by a subfronted mass (arrowed). At necropsy a glioma was found in the left posterior temporal area, and a subfrontal meningioma also showir

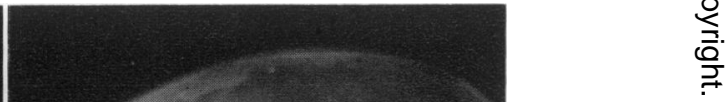




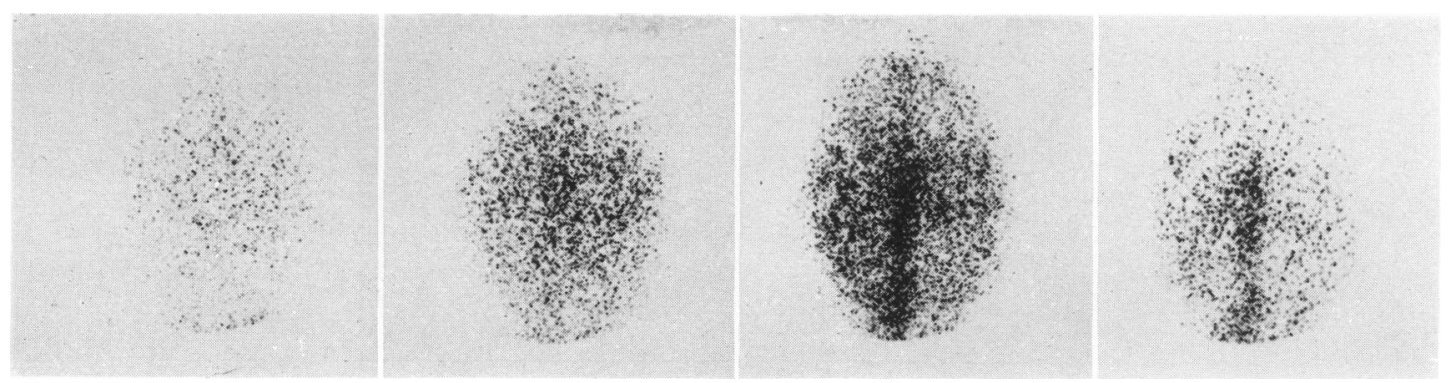

FIG. 4. Normal rapid sequence brain scan. Four vertex views show arterial, capillary, venous and later venous phases following an intravenous bolus of ${ }^{99 \mathrm{~m} T c}$. Note the symmetrical distribution of radioactivity.

in ten patients and compared in accuracy with other techniques such as ophthalmodynamometry, and Dopler ultra-sound. They also showed one false positive out of twenty-one normals.

Turning to brain scanning applied to head trauma and the diagnosis of subdural or extradural hematomas it is doubtful if at the moment brain scanning has a vital role. The chronic subdural hematoma will produce a characteristic abnormality on the brain scan with a crescentic peripheral increase of activity often high up near the vertex. This appearance, however, may not be present during the first 24 or $48 \mathrm{hr}$ of illness and moreover may be produced by soft tissue lesions overlying the skull vault. The brain scan, therefore, is of most use in patients suspected of chronic subdural hematoma (as opposed to acute head trauma). Arkles, Andrews \& Steven (1972) reviewing twenty-three reported 'subdural hematomas', however, found proof of this diagnosis in only twelve; that is, there were eleven false positives. Vaughan et al. (1971) were successful in all of their small series, but $I$ think the more general view is that the scan is not a reliable index of cerebral injury in acute head trauma and that the diagnosis of chronic subdural hematoma is liable to mis-interpretation due to rotation and other technical faults.

\section{Brain scanning in inflammatory and other lesions}

There is inadequate space to review the large number of conditions which may be associated with an abnormal brain scan. It should be pointed out, however, that abnormalities of both the soft tissue and skull vault as well as the underlying meninges may cause focal areas of increased activity and these should not be misinterpreted as representing a cerebral lesion (Tow \& Wagner, 1967). Most intracerebral abscesses give strongly positive brain scans (Jordon, James \& Hodges, 1972) but there is evidence that the scan may not become positive for 1-2 weeks and may remain positive long after surgical evacuation (Overton, Haynie \& Snodgrass, 1965).
Both meningitis and encephalitis may be associated with often rather diffuse areas of increased activity (McLaughlin, Crocker \& Morris, 1972; Cuzer \& Ioannides, 1971).

\section{Liver scanning}

Radioisotope scanning of the liver is perhaps the second most common organ scanning procedure. Like brain scanning it is a simple, cheap and atraumatic way of getting a picture of an organ which is difficult to investigate radiologically. However, as will become apparent, its accuracy is not as great as the brain scan. It is possible that further advances in radiopharmaceuticals may increase the accuracy of detection of various diseases in the future.

\section{Radiopharmaceuticals}

The usual way to visualize the liver depends on its ability to clear colloidal particles from the blood into the Kupffer cells. Various types of particle have been used, including radioactive colloidal gold (Stirrett, Yuhl \& Cassen, 1954), heat denatured human serum albumin (Benacerraf et al., 1957) and probably the most widely used agent, technetium-labelled sulphur colloid. ${ }^{113 m}$ Indium-labelled ferrous hydroxide is also in use, but probably less widely than technetium. Such particulate matter, when injected intravenously is cleared by the whole of the reticuloendothelial system of which the liver forms only one part. Other organs which are visualized are, therefore, the spleen and bone marrow. Both the rate of clearance and the trapping of colloidal particles by different organs are influenced by particle size. The most commonly used agents show a distribution of $80 \%$ or more of radioactivity located in the liver, $10-15 \%$ in the spleen and approximately $5 \%$ in the bone marrow. Since the extraction ratio for any one preparation remains constant for normal livers the hepatic uptake of labelled colloidal particles can be used as a measure of hepatic blood flow (Shaldon et al., 
Fig. 5. Brain scan in cerebral infarct. (a) Four rapid sequence vertex views taken at 3, 7, 15 and 20 sec showing reduced radioactivity reaching the right hemisphere (right of picture). (b) Conventional scan at 60 min showing ill-defined area of increased activity in the right temporal area (arrowed). This 50-year-old patient had an old left hemiparesis following ligation of her internal carotid artery with recent exacerbation probably due to further infarction.

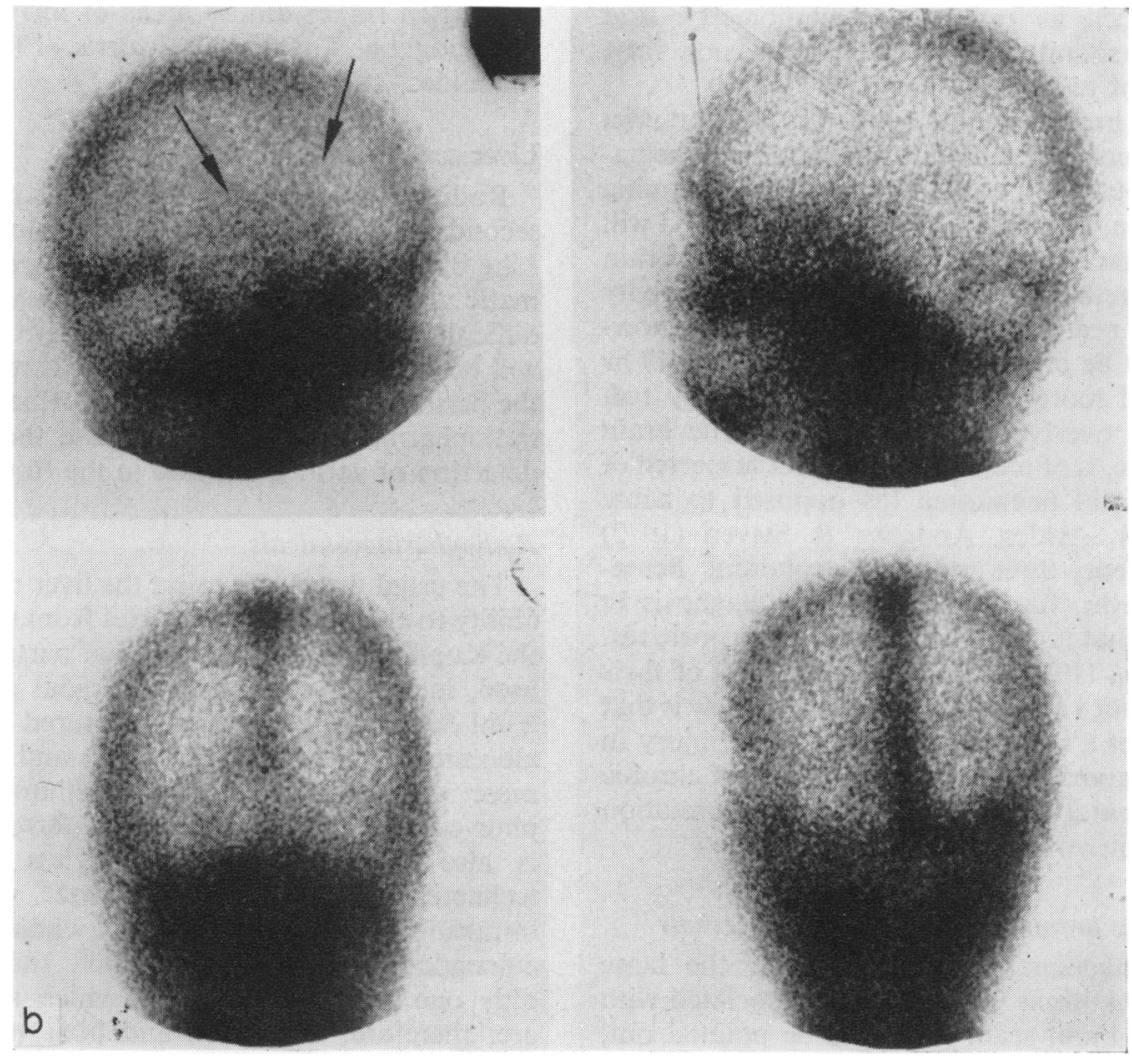

Fig. 5b.

1961). In the case of the abnormal liver, however, the significance of clearance rates of the blood and hepatic uptake are difficult to interpret since there may be alteration not only in hepatic blood flow but in extraction efficiency.

An alternative radiopharmaceutical originally introduced by Taplin, Meredith \& Kade (1965) is radio-iodinated Rose Bengal. This dye, introduced as a measure of hepatic function, is metabolized byc hepatocytes and excreted in the bowel. Scans using $₫$ this agent will therefore show both liver outline, ? visible at about 15 or $20 \mathrm{~min}$ and, in later scans, $T$ radioactivity can be seen in both the biliary tract and $\underset{\mathbb{D}}{O}$ the small bowel. 


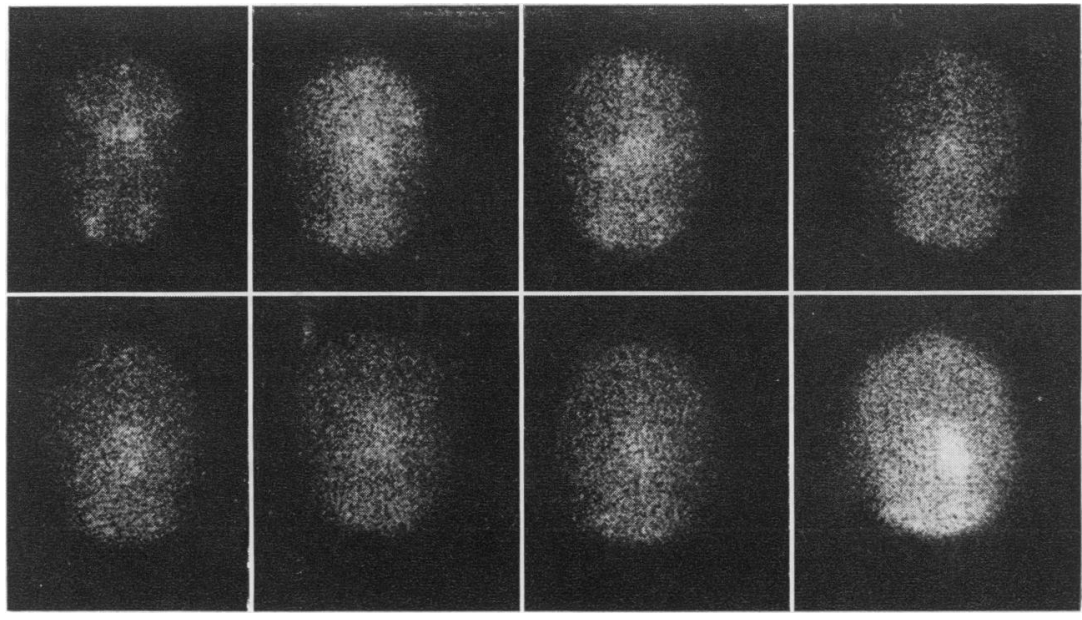

FIG. 6. Rapid sequence brain scans in vascular glioma. A series of frontal views showing the passage of a bolus of radioactivity through arterial and venous phases (first four views). The glioma appears in later pictures as an area of increased radioactivity lying centrally.

A further radiopharmaceutical occasionally applied to liver scanning is ${ }^{75}$ seleno-methionine. This labelled amino acid, commonly used for pancreatic scanning, is metabolized by hepatocytes, but also by certain neoplasms of the liver, principally hepatomas (see below).

\section{The normal liver scan}

The typical appearance of a normal liver scan is illustrated in Fig. 7. The outline of the liver is smooth with the exception of a notch adjacent to the gall bladder bed. Some diminution in activity between right and left lobes corresponds to the aorta and inferior vena cava, and also the porta hepatis. One of the problems of assessing liver scans is the variability in shape of an organ which is moulded by surrounding structures. The costal margin may produce an indentation on the lateral aspect which may be mistaken for liver replacement. The diaphragmatic surface of the liver shows considerable variation, and the over-lapping shapes of right and left lobes in the lateral view can cause difficulties of interpretation.

The liver size can be accurately assessed from the liver scan and calculations deriving liver volume from the scan correlate well with autopsy measurements (Rollo \& Deland, 1968).

Displacements of the liver by adjacent masses or collections of fluid may be shown and occasionally for this purpose simultaneous scanning of lungs and liver may be helpful.

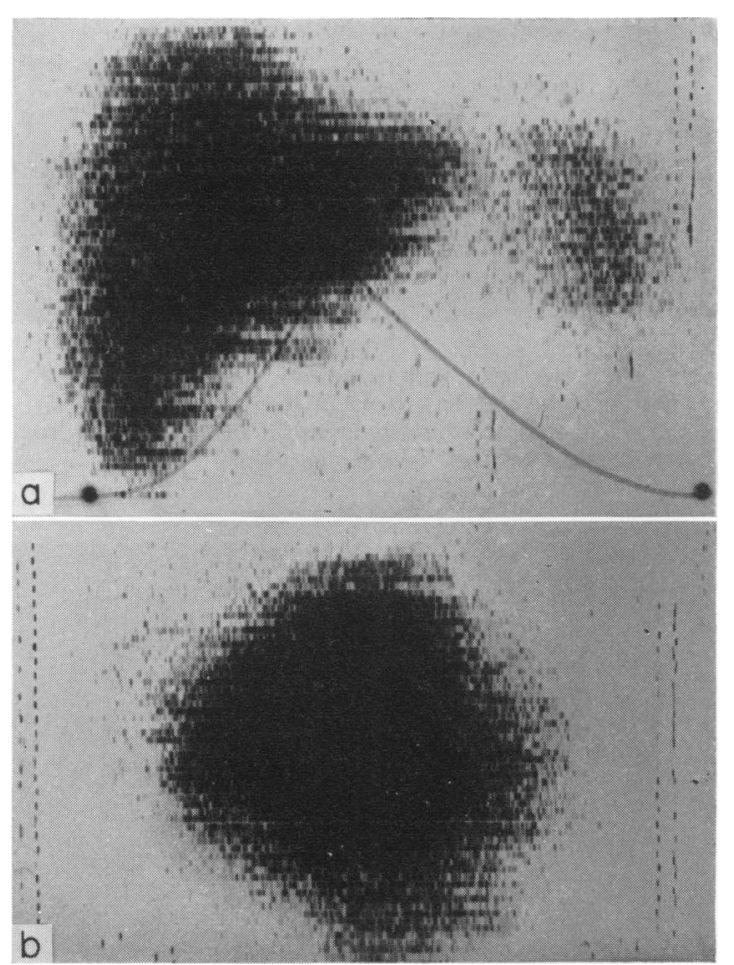

FIG. 7. Normal liver scan. (a) Anterior scan using ${ }^{89 m}$ Tc sulphur colloid shows right and left lobes of the liver. The spleen is poorly outlined on this scan since it is lying posteriorly. (b) Right lateral view. 


\section{Focal liver replacement}

The replacement of liver parenchyma by malignant growth, benign tumour or inflammatory tissue will result in the same appearance on the liver scan; a circumscribed 'cold' area (Fig. 8). The accuracy with which lesions are detected depends on their size and position (Vidrih \& Higgins, 1971). This accuracy is not very great in terms of the size of the lesion in that an area of liver replacement must be at least $4.5 \mathrm{~cm}$ in diameter if it lies in the centre of the right lobe and the smallest lesion which could be expected to be detected is one of $1.8 \mathrm{~cm}$ in diameter. Marginal im-

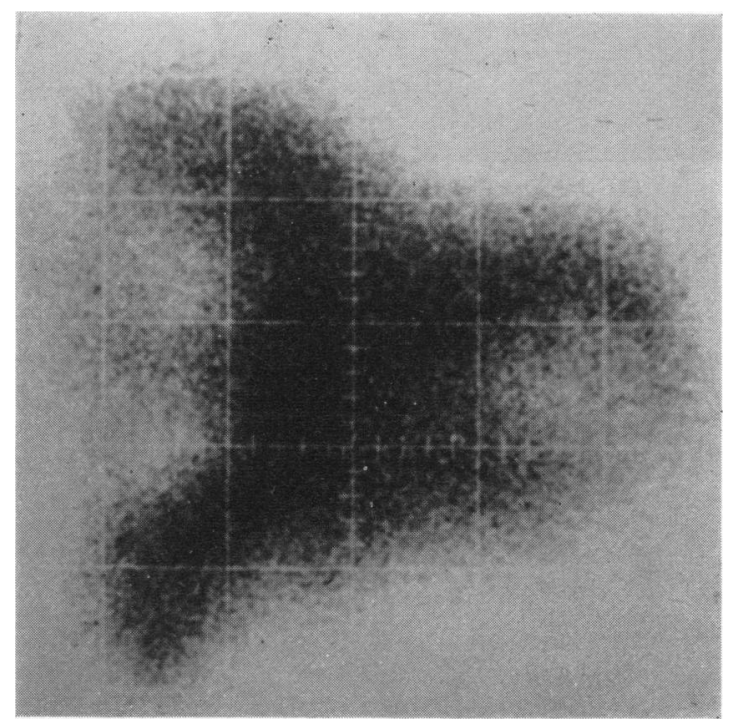

FIG. 8. Liver scan with metastatic deposits. Anterior view of right and left lobes of liver (gamma camera) showing multiple rounded areas of decreased activity representing areas of liver replacement.

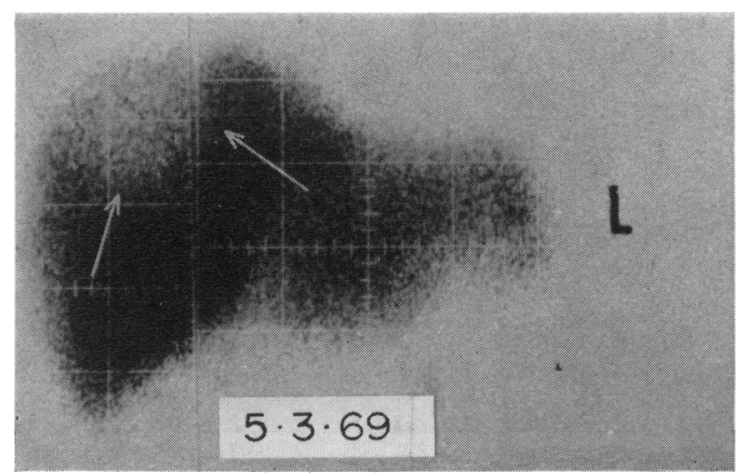

provements can be obtained by taking pictures in arrested respiration, but even with this improvemen it is obvious that small lesions will be missed. Figure? for the 'accuracy' of liver scanning are therefore of doubtful value. Published correlations of liver scan $\vec{F}$ with necropsy data claim that $80-90 \%$ of proved metastases are detectable by scanning (Nagler Bender \& Blau, 1963; McAfee, Ause \& Wagner 1965; Powell \& Mangum, 1972).

Our own experience applied to 75 patients with breast carcinoma has shown much poorer figures (Nathan, 1972). In ten patients with proven deposits at necropsy or laparotomy the scan was abnormal in five and doubtful in a further two, but in all fiveु positive scan patients the diagnosis was apparen clinically.

The application of liver scanning to suspecte liver abscess can be very valuable. In most cases the lesion is clearly seen and the scan can be used to aik aspiration or surgical exploration and subsequent follow up (Fig. 9).

\section{Cirrhosis of the liver}

Liver scanning using a colloid produces a fairly characteristic picture in cirrhosis of the liver. The liver is frequently small and shows an irregular distri bution of radioactivity, trapping of colloid begng reduced throughout. The spleen is usually enlarged and traps relatively more colloid and, unlike the mal scan, the spinal marrow is often clearly seen due to the relatively poor clearance of colloid by the live $\bar{\rho}$

One of the problems which presents in cirrhotie patients is the diagnosis of coincident hepatoma?

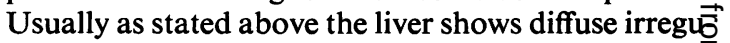
larity of uptake of colloid but may at times show more focal defects, still due to cirrhosis. On the colloie scan this appearance may be indistinguishable frori a hepatoma. Under these circumstances a repeas

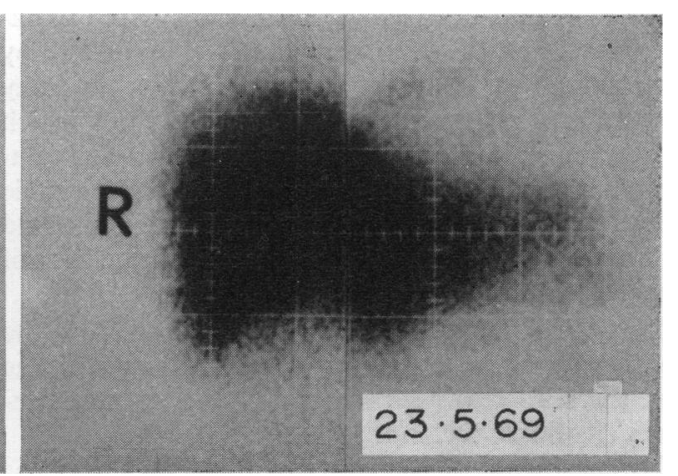

FIG. 9. Amoebic abscess. Liver scans of 33-year-old Indian admitted with pyrexia, slight jaundice and a tender liver. On the left is the initial scan showing a cold area in the right lobe (arrowed). The subsequent scan was taken after a course of treatment for an amoebic abscess. 
examination using ${ }^{75}$ seleno-methionine may be helpful. The hepatoma usually will metabolize the labelled methionine, whereas fibrous tissue or inflammatory lesions will appear as a cold area. If, therefore, the lesion seen on the colloid scan 'fills in' with selenomethionine then this indicates the likelihood of hepatoma (Eddleston et al., 1971) (Fig. 10).

\section{Lung scanning}

\section{Radiopharmaceuticals and technique}

The earliest investigations on the lung with radionuclides used radioactive gases. Knipping et al. (1955) studied pulmonary disease by using radioactive xenon with single counters over the chest. Such studies using radioactive xenon with single or multiple counters are still in use for physiological observations. West (1960) and Dollery \& West (1960) used the short-lived isotopes of oxygen and carbon available from a cyclotron to make fundamental observa-

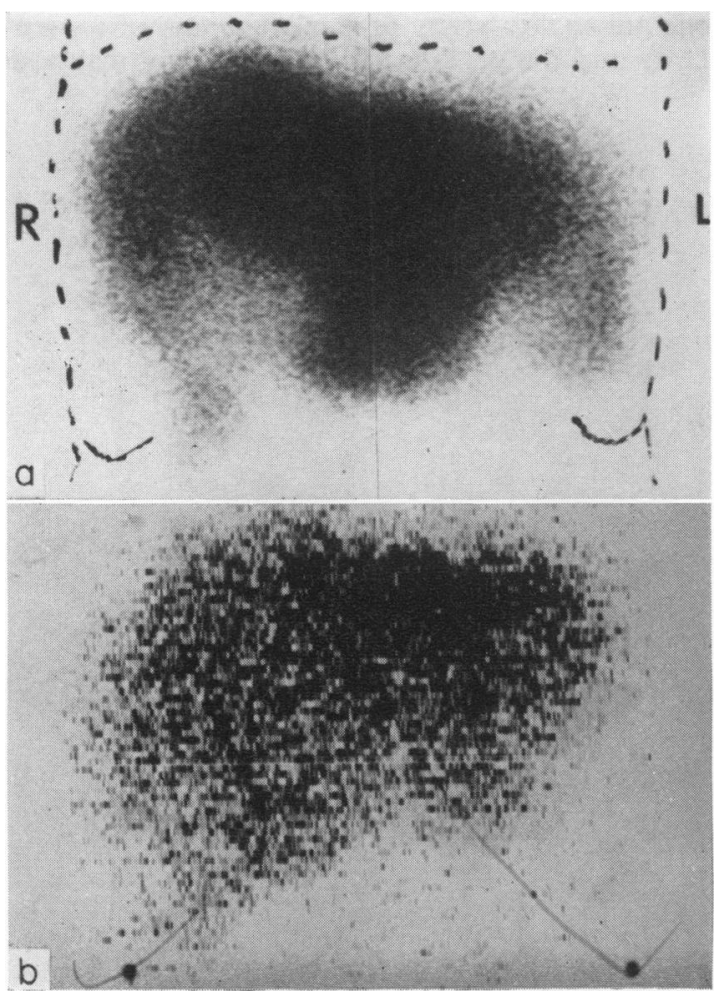

FIG. 10. Cirrhosis of the liver with hepatoma. (a) ${ }^{99 \mathrm{~m} T c}$ colloid liver scan of 39-year-old patient presenting with haematematosis, ascites and abnormal liver function tests. This shows a slightly large liver with a 'cold' area in the lower right lobe. The spleen is moderately enlarged. (b) Same view using ${ }^{75} \mathrm{Se}$ seleno-methionine showing 'filling in' of cold area. Hepatoma subsequently confirmed. tions on the physiology of pulmonary blood flow and gas exchange. Such work used either fixed detectors or scintillation counters which moved from top to the bottom of the lung to give numerical data. With the introduction of metabolized iodinated macroaggregates of human serum albumin by Taplin et al. (1964) and Wagner et al. (1964) lung scanning, i.e. an image of the lung produced by a linear scanner, became available as a clinical procedure for assessing regional pulmonary blood flow. The principle behind the development of macroaggregates is that of injecting intravenous particles of a size between $15 \mu$ and $70 \mu$ which become trapped in the lung capillary bed. Since the particles are uniformly mixed with the blood leaving the right ventricle their distribution represents the relative distribution of pulmonary blood flow 'frozen' at that moment in time. Since the particles remain trapped in the capillary bed for some hours scanning can therefore be carried out at leisure. The macroaggregates of human serum albumin are still in wide use, although the radioactive labelling is now usually by means of technetium. Recently introduced are metabolizable microspheres, which have the advantage of a constant size, although it is doubtful if in normal clinical practice this provides any great advantage. Macroaggregates or particles can also be made using ferric hydroxide and the labelling by ${ }^{113} \mathrm{~m}$ indium or technetium.

Radioactive gases, mainly ${ }^{133}$ xenon, are now coming into wider use again, apart from their use by physiologists, due to the increasing potentialities of the gamma camera. Here the data processing system facilities coupled with the use of the gamma camera may give not only an organ scan but also numerical physiological data. The only gas widely available for this use, however, is ${ }^{133}$ xenon which has a rather low energy gamma radiation which limits its usefulness. $81 \mathrm{~m}$ Krypton, which has a very short half-life $(13 \mathrm{sec})$, is available from a cyclotron, but again is inconvenient for routine use. Such radioactive gases can be used to obtain a record of regional pulmonary blood flow when injected intravenously dissolved in saline, and the same gas can also be used for making assessments of ventilation and gas exchange (see below).

Ventilation studies can also be performed using a radioactive aerosol (Taplin \& Poe, 1965). Such an aerosol can be labelled using technetium and used in association with pictures performed by a gamma camera. Abnormal patterns due to chronic lung disease can be recorded and excess aerosol is seen in areas of narrowing or deformed parts of the bronchial tree.

\section{The normal lung scan}

A typical preparation for performing a lung scan contains $5 \mathrm{mg}$ of human serum albumin in the 
form of macroaggregates, ranging from 15 to $70 \mu \mathrm{m}$ in size, labelled with technetium. The macroaggregate is injected intravenously with the patient either lying or sitting. These two positions will, however, result in a different distribution of particles, since there is greater perfusion of lung bases when the patient is erect. The macroaggregate should be agitated before injection and should not be mixed with blood in the syringe. The appearance of the normal perfusion lung scan is illustrated in Fig. 11. Both frontal and lateral views should be obtained. Points to note are that the margins of the lungs are smooth with relatively more radioactivity at the bases than the apex. The mediastinum appears as an area of low radioactivity. The heart is clearly outlined on the anterior scan and may also infringe on the antero-inferior margin of the left lateral view. The posterior view shows the spine with straight margins of the lung on either side. The diaphragm may show 'scalloping' due to respiratory movement. Changes in the appearance of the mediastinum may be due to enlargement of the heart, mediastinal masses and even markedly enlarged pulmonary arteries may be visible. The normal lung scan characteristically shows no focalœ diminution or cold areas, but as pointed out by Webber et al. (1972) $20 \%$ of normal volunteers may have 'minor abnormalities' on their scans and in $4 \%$ there is what is described as a substantial defect.

Lung with pulmonary embolic disease

The major application of lung scanning is in $\frac{\bar{\sigma}}{\mathrm{c}}$ pulmonary embolic disease. This is a natural use of $\vec{\Phi}$ this technique in a clinical situation which is other-을 wise difficult to diagnose with any accuracy. It hasis been shown that up to $35 \%$ of post-operative $\vec{\circ}$ patients suffer from venous thromboses in the leg $\overrightarrow{-}$ (Flanc, Kakkar \& Clarke, 1968). The number of $\vec{\omega}$ patients who suffer from pulmonary embolic disease as a result of this is uncertain, but minor emboli are $\frac{O}{3}$ undoubtedly very common in hospital populations. and recent emboli are found in between $20 \%$ and $\frac{10}{6}$ $50 \%$ of necropsies (Freiman, Suzemoto \& Wessler, or 1965; Rywlin, 1970). The chest X-ray is frequently non-contributory, but may show enlargement of $\frac{+}{\infty}$ one pulmonary artery or a relative area of avascularity and the position of the diaphragm may also

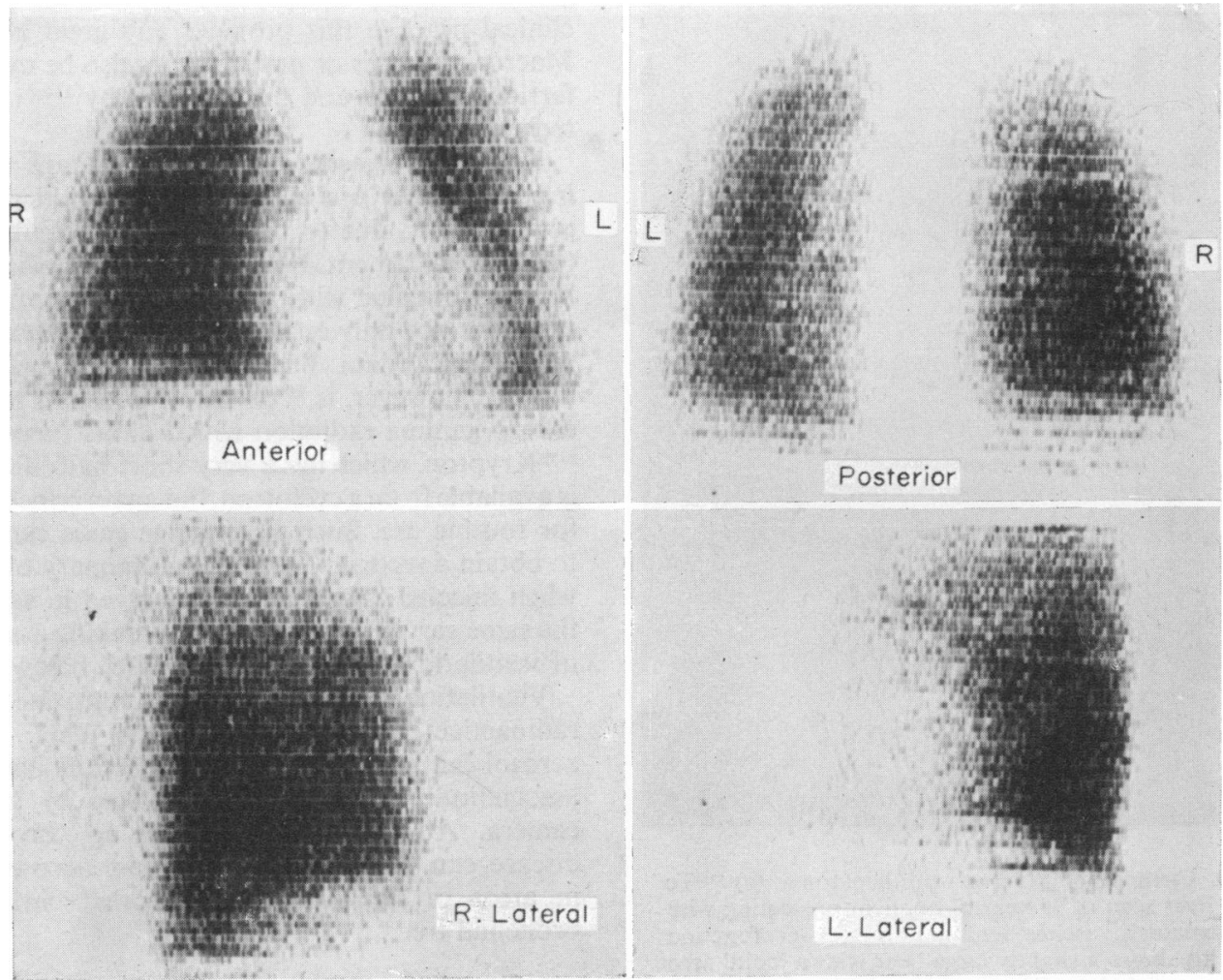

FIG. 11. Normal lung scan. Four views are shown, the anterior, posterior and both laterals. Note the smooth periphery of the lungs and distribution of radioactivity. The heart in this patient was slightly large and projects into the anterior lung field on the left lateral view. 
change. In this situation the lung scan characteristically shows well demarcated, often segmental, defects of perfusion (Fig. 12). These are usually multiple, often causing 'bank-like' areas of decreased activity to appear on the scan. Where the chest $X_{2}$-ray shows clear lung fields, then one can usually ascribe these appearances to focal defects of perfusion due to pulmonary emboli. Where, however, an avascular area on the scan corresponds to an opacity seen on the chest X-ray the situation is more complex. Areas of collapse or pneumonia may show decreased pulmonary blood flow and therefore the scan of this lesion is not diagnostic. In most cases of pulmonary embolic disease, however, further avascular areas are present elsewhere due to the liberation of emboli which have not caused infarction, and this may
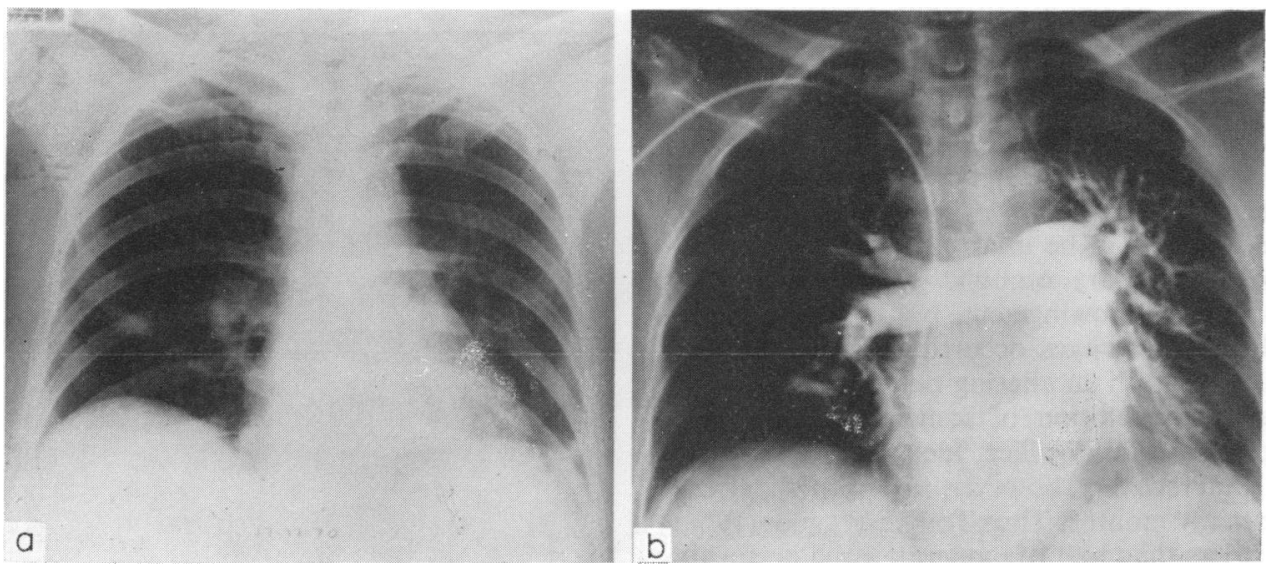

FIG. 12. Chest X-ray, angiogram and lung scan in acute pulmonary embolic disease. The patient was admitted to hospital with a venous thrombosis in her leg. While in hospital she had an acute pulmonary embolus. (a) Chest X-ray showing a small opacity in the right mid zone. (b) Pulmonary angiogram showing filling defects in the right pulmonary artery and occlusion of branches. (c) Lung scan showing defects of perfusion in mid zone and lower zone of right lung. (d) Posterior views of same patient showing normal scan on admission, 3 December 1970, a defect of perfusion on 17 December 1970 due to an acute embolus and a gradually resolving perfusion defect of the right lower lobe is shown on 22 December 1970 and 5 January 1971.
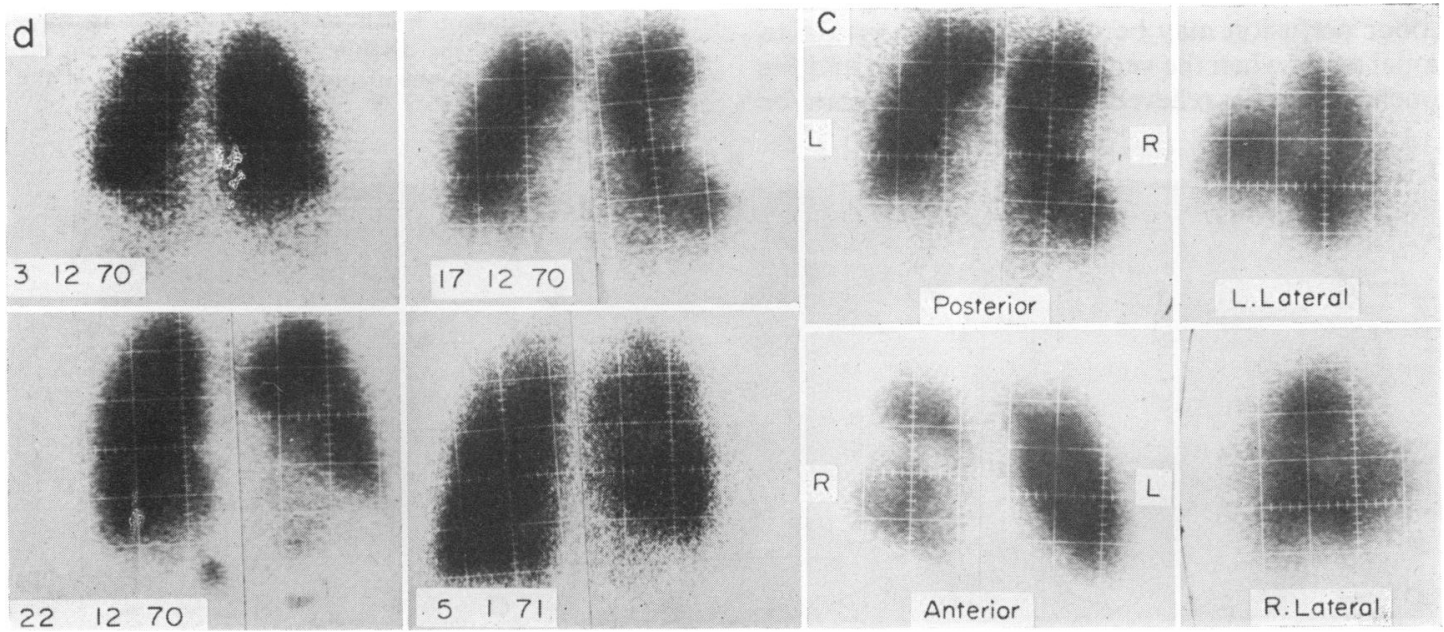

FIG. $12 \mathrm{c} \& 12 \mathrm{~d}$. 
enable a diagnosis to be made. The co-existence of pulmonary embolic disease and chronic lung disease makes interpretation of a lung scan very difficult and here repeated scans may be required to look for changes of perfusion pattern.

The perfusion defects seen on the lung scan correlate well with those shown on pulmonary angiography (McIntyre \& Sasahara, 1971). Experience of using both techniques suggests that the lung scan is more sensitive, although obviously not so specific an investigation as the arteriogram. Defects will be seen on the scan where an examination of the arteriogram shows no obvious abnormality. This is readily understandable in view of the superimposition of relatively small vessels on the angiogram and the difficulty of identifying an occlusion of such small branches.

Lung scanning can be used to follow the natural history of pulmonary embolic disease (Fig. 12). Sequential scans following acute pulmonary embolus frequently show changes occurring during the first few days, often with an altering pattern of perfusion defects and a resolution of some areas occurring fairly rapidly (Secker-Walker, Jackson \& Goodwin, 1970). A total recovery, however, to a normal pattern may take many months. Thus Tow \& Wagner (1966) found that less than half of moderate sized perfusion defects following an acute pulmonary embolus had completely resolved at the end of 4 months.

\section{Chronic lung disease}

Since changes in ventilation will produce a concomitant change in perfusion many types of chronic lung disease will produce an abnormal lung scan. This situation is most dramatically illustrated in patients with bronchial asthma, where if lung scanning is carried out during an acute attack, focal areas of poor perfusion may be observed which return to normal again when the ventilation is restored and the bronchospasm is relieved. Lung scanning can be applied to bullous emphysema where the possibility of surgery is contemplated and a relative blood flow to the two lungs is recorded by the lung scan. Probably the most useful mode of investigation in these patients, is however, to look at both perfusion and ventilation (Fig. 13). This can be done either separately or using ${ }^{133}$ xenon for ventilation studies followed by macroaggregates, or xenon can be injected intravenously during breath holding, thus giving a record of perfusion, since the gas is liberated

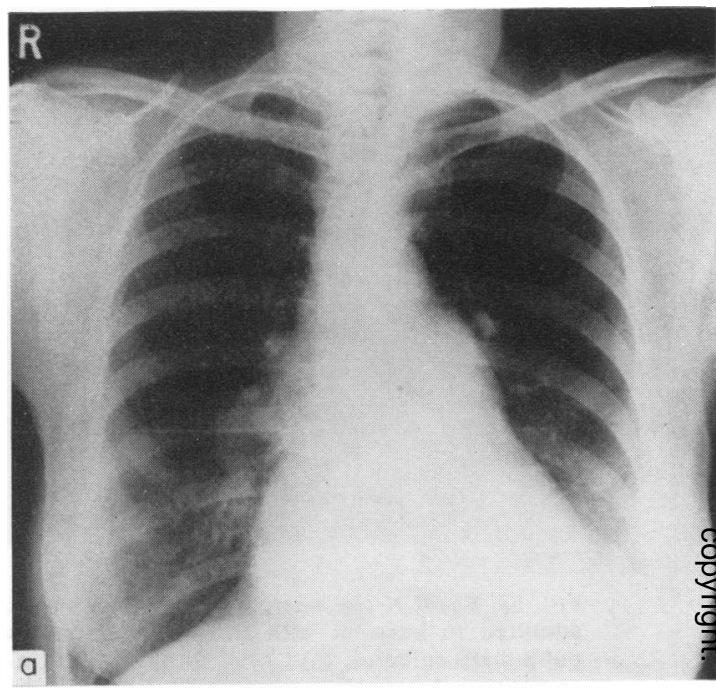

FIG. 13. Perfusion and ventilation scans in chronic bronchitis. (a) Chest X-ray on 60-year-old chronic bronchitic showing large pulmonary arteries. (b) Perfusion scan ( ${ }^{90 \mathrm{~m}} \mathrm{Tc}$ macroaggregates) showing irregular perfusion with a defect in the left mid zone (on left of picture). (c) Ventilation scan $\left({ }^{183} \mathrm{Xe}\right)$ showing poor ventilation in the same area. (d) Ventilation 'wash-out'. This is one frame from a series showing the disappearance of xenon from the right lower lobe (right of picture) and retention in the rest of the lungs.

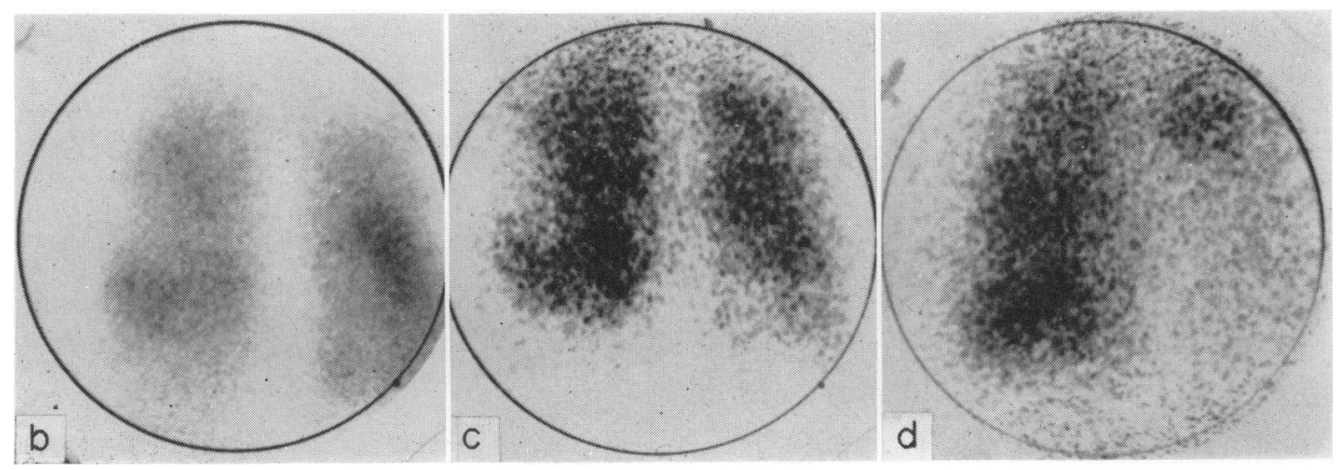

FIG 13 b, c, d. 
in the alveoli in proportion to their blood flow. The subsequent wash-out of this gas from the alveoli can be used as a measure of regional ventilation (Farmelant \& Trainor, 1971; Medina et al., 1969).

\section{Lung scanning in other diseases}

Lung scanning has been applied to cases of bronchogenic carcinoma in attempts to assess operability and/or progress, but it is doubtful if this application has a very useful place. Lung scanning has also been applied to pulmonary hypertension secondary to raised left atrial pressure, where the relative counts over the base and apex can be related to changes in blood flow induced by increases of left atrial pressure (Friedman \& Braunwald, 1966). A further application of lung scanning is in the comparatively rare cases of pulmonary hypertension due to vascular changes in the pulmonary capillary bed. These may be either in the form of 'idiopathic' or primary pulmonary hypertension, or secondary to chronic thromboembolic disease. It can be shown that the distinction between these two groups can be readily made on the basis of the lung scan and this distinction correlates well with the results of arteriography (Wilson et al., 1973).

\section{Bone scanning}

It has long been known that a number of radionuclides show bone localization, and work with ${ }^{45}$ calcium by Pecher in 1942 showed that this isotope had its highest concentration in areas of new bone formation. No suitable isotope of calcium is available for scanning, but a large number of other radionuclides have been explored. All depend on local increases in areas of high bone turnover where they exchange with portions of the hydroxy-apatite crystals. Local increases of radioactivity are seen in relation to fractures, osteomyelitis, primary tumours of bone, and most important in its clinical applications, in the neighbourhood of metastatic tumour deposits.

\section{Radiopharmaceuticals}

The obvious tracer to outline the skeleton and exchange with the calcium present in the hydroxyapatite crystals would be a radioactive calcium, but no suitable isotope exists with desirable physical characteristics. Strontium, however, has been shown to behave in a similar fashion to calcium in the body and two isotopes of strontium are in use for bone scanning. ${ }^{85}$ Strontium with the half-life of 65 days has the disadvantage of a delay of at least $48 \mathrm{hr}$ between the moment of injection and the scan. Small amounts of this isotope are also excreted into the bowel. An advantage with the use of this isotope, however, is the fact that blood levels of radioactivity fall to a low point, thus allowing a clear visualization of the skeleton and any lesions. ${ }^{87 \mathrm{~m}}$ Strontium with a half-life of $2.8 \mathrm{hr}$ is available from a generator and allows scanning earlier after injection. ${ }^{18}$ Fluorine is a cyclotron produced radioisotope with a half-life of $2 \mathrm{hr}$. Due to the method of production and its short half-life this isotope is not generally available, but the quality of scans produced by ${ }^{18}$ fluorine is better than that when strontium is used (French \& McCready, 1967; Galasko et al., 1968; Ronai, Winchell \& Anger, 1968). In the last year or so a number of other agents have been suggested and assessed on an experimental basis. ${ }^{67}$ Gallium and ${ }^{68}$ gallium have been used as bone-seeking isotopes for a number of years (Dudley \& Maddox, 1949). Isotopes of barium and dysprosium have also been used for the same purpose (Spencer, Lange \& Treves, 1971; Subramanian et al., 1971a).

The most recent development in this field has been the exploration of various phosphate compounds which could be labelled with technetium. Work by Subramanian \& McAfee (1971) showed that complex of tripolyphosphate and stannous chloride could be labelled with technetium and produced clear images of the skeleton at $3 \mathrm{hr}$ with considerably higher activity around new bone in callus. Since then a number of agents based on phosphates have been investigated, including long chain polyphosphates (Subramanian et al., 1971b) and phosphonates (Yano et al., 1972). At the moment it is still uncertain whether these agents differ greatly from each other. Clinical trials show excellent skeletal detail with individual ribs and vertebral bodies being clearly shown. There seems little doubt that using such agents bone scanning will be possible on a wider scale than at the moment.

\section{Bone scanning for metastatic tumour}

As outlined the major application of bone scanning is in the detection of occult bony metastases. The mechanism behind the local increase in bone seeking agents in the region of bone tumours has been investigated by Charkes, Sklaroff \& Young (1966) who found a close relationship between the presence of immature reactive bone formed in response to tumour cells and localized increased concentration of ${ }^{85}$ strontium. The appearance of an abnormal bone scan may precede radiological abnormalities. This has been shown by a number of workers. Thus Charkes, Sklaroff \& Young (1966) found $21 \%$ of abnormal scans, in patients suffering from back pain and a cancer elsewhere, who had negative X-rays. Similar figures for positive scans with negative radiology have been noted by De Nardo (1966), French \& McCready (1967) and Galasko et al. (1968). In a follow up of such cases the lesion will become apparent radiologically up to 18 months later. 
If bone scanning is used as a screening procedure preceding surgery or the institution of systemic therapy, then the whole or major part of the skeleton must be seen. This requires some form of whole body scanning, or alternatively the gamma camera can be used either with a pin hole collimator or to take multiple views. Comparison of the various techniques has been reviewed by Krishnamurthy et al. (1972) and Merrick (1973). Galasko (1969) has applied the method of multiple gamma camera views in surveys of cancer of the breast. He demonstrated that in fifty patients with 'early', i.e. radiologically negative, apparently localized disease, twelve patients had positive bone scans, all of which on follow up eventually proved to be radiologically abnormal. Investigations of patients suffering from bronchogenic

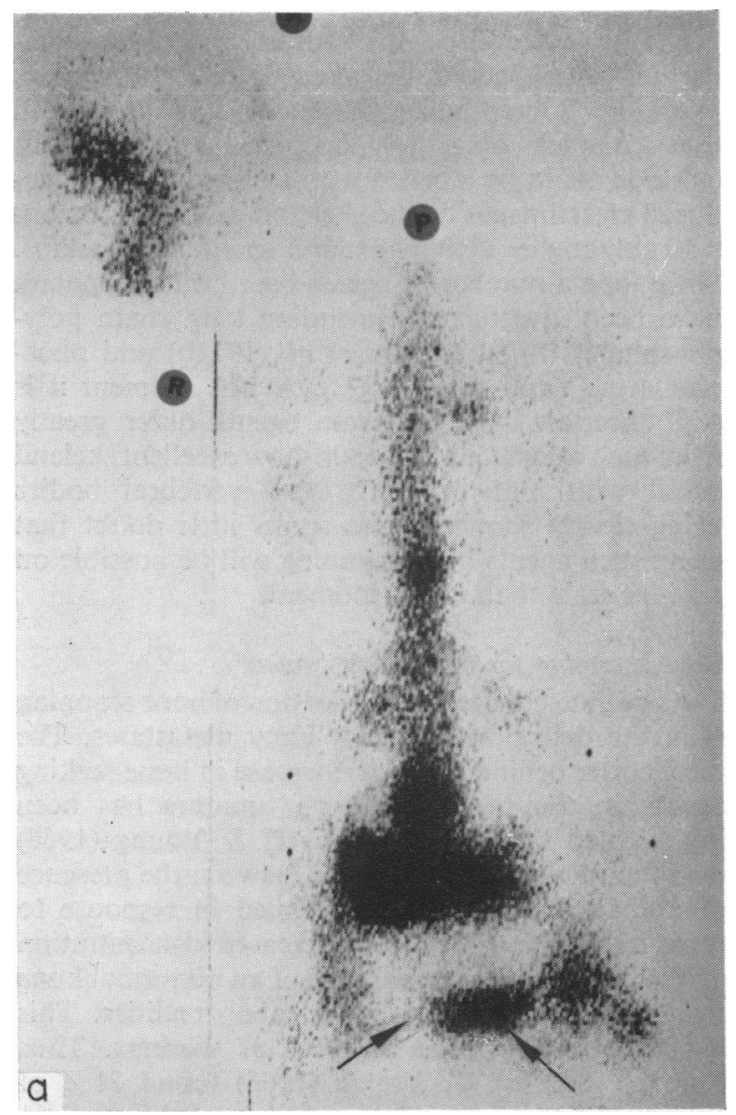

Fig. 14. (a). Posterior bone scan ( ${ }^{18}$ fluorine) of spine, pelvis and upper femora in 66-year-old woman with metastatic breast carcinoma. Areas of increased activity are seen in the lower spine and sacroiliac regions, the left upper femur, the dorsal spine and ribs. Arrows indicate ${ }^{18} \mathrm{~F}$ in the bladder (the skull is seen upper left). (b) Same patient; pelvis. There is a change of bone texture in the right sacroiliac region.

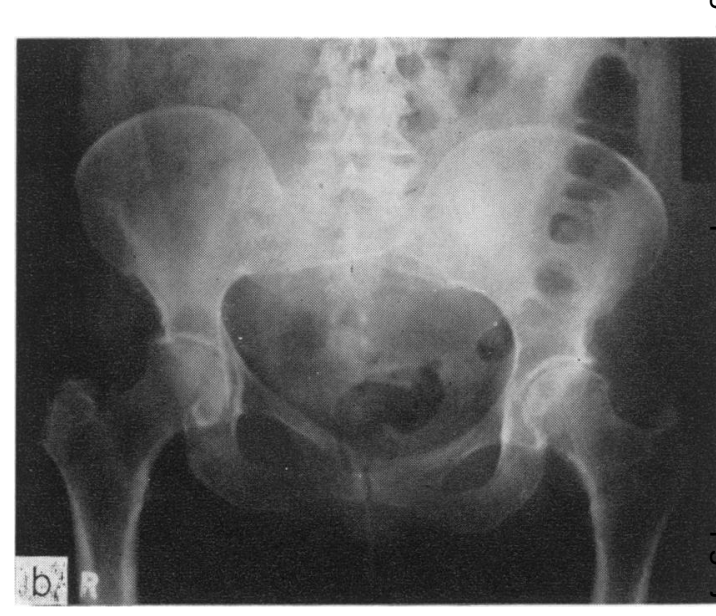

FIG 14b.

carcinoma (Sauerbrunn et al., 1972) and also carci $\stackrel{\overrightarrow{0}}{\circ}$ noma of the prostate show a similar incidence of occult bone tumour discovered by bone scanning (Roy, et al., 1971). The number of patients who show $=$ radiological bone lesions with negative bone scans is very small apart from those caused by benign lesions $\overrightarrow{50}$ such as bone islands. Charkes, Sklaroff \& Youg ge (1966) suggest that in $5 \%$ of patients a scan of radiolucent area is negative. They say that in early phases of bone destruction with little in the way of reactive new bone the scan may be negative of minimally positive. Having gone through a phase of marked bone reaction it may then become a sclerotic lesion with again little in the way of bone turnoverō The scan, having previously been markedly positive 3 then becomes either negative or shows a minimat localization. Experience using ${ }^{18}$ fluorine at the. Hammersmith Hospital, however, shows that the incidence of negative scans with positive radiologica? findings is very low (Merrick, 1973). An illustration of a positive bone scan due to metastatic tumour is given in Fig. 14.

\section{Scanning in other bone disorders}

Since a positive bone scan is associated with the presence of calcifying osteoid it follows that this includes a variety of bone lesions. It is for this reasoly important in bone scanning to make a strict comp parison between radiological and scanning findingș

Primary tumours of bone may be delineated by bone scanning and this subject has been explored by Harmer et al. (1969). These authors found that the were able to depict the extent of primary tumours of bone by using ${ }^{18}$ fluorine and that bone scanning could also indicate the recurrence of tumour following treatment with radiotherapy. 
Paget's disease shows marked increased uptake of radioisotopes (Fig. 15). Other primary diseases of bone such as fibrocystic disease and infective lesions of bone will also be shown on scanning. Hypertrophic pulmonary osteoarthropathy may also be identified on a bone scan (Chaudhuri, Schapiro \& Christie, 1972).

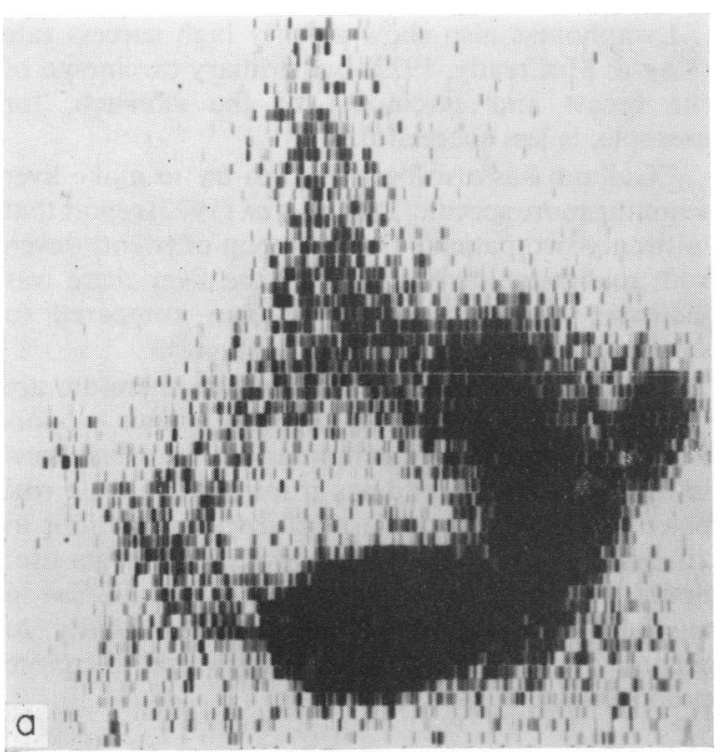

FIG. 15. (a) Bone scan $\left({ }^{18} \mathrm{~F}\right)$ of lower lumbar spine and pelvis showing marked increase of radioactivity in the left hemipelvis. The oval central area represents radioactivity in the bladder. (b) Pelvis of same patient showing coarse trabecular pattern in left ileal bone due to Paget's disease.

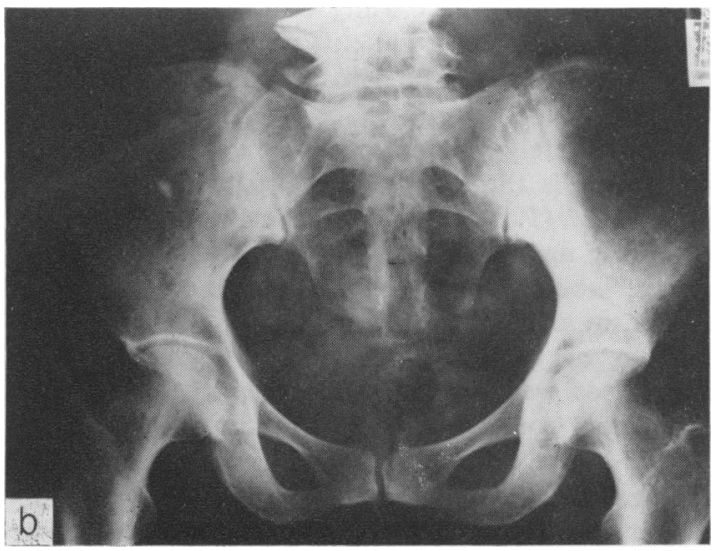

Fig. 15b
Degenerative arthritis is associated with new bone formation and therefore will cause local increased activity of radionuclides (Fig. 16). This fact has been used to study changes in various types of arthritis (Muheim \& Crutchlow, 1971).

Bone scanning, or alternatively surface counting over bone, has been used in trying to assess union or non-union in fractures. Illingworth \& Schiess (1971) found that strontium achieved maximum localization over fractures at 6-8 months. Examining fractures at $24 \mathrm{hr}$, however, using strontium as a bone localizing agent, was not useful in predicting the subsequent union or non-union of fractures of the tibia.

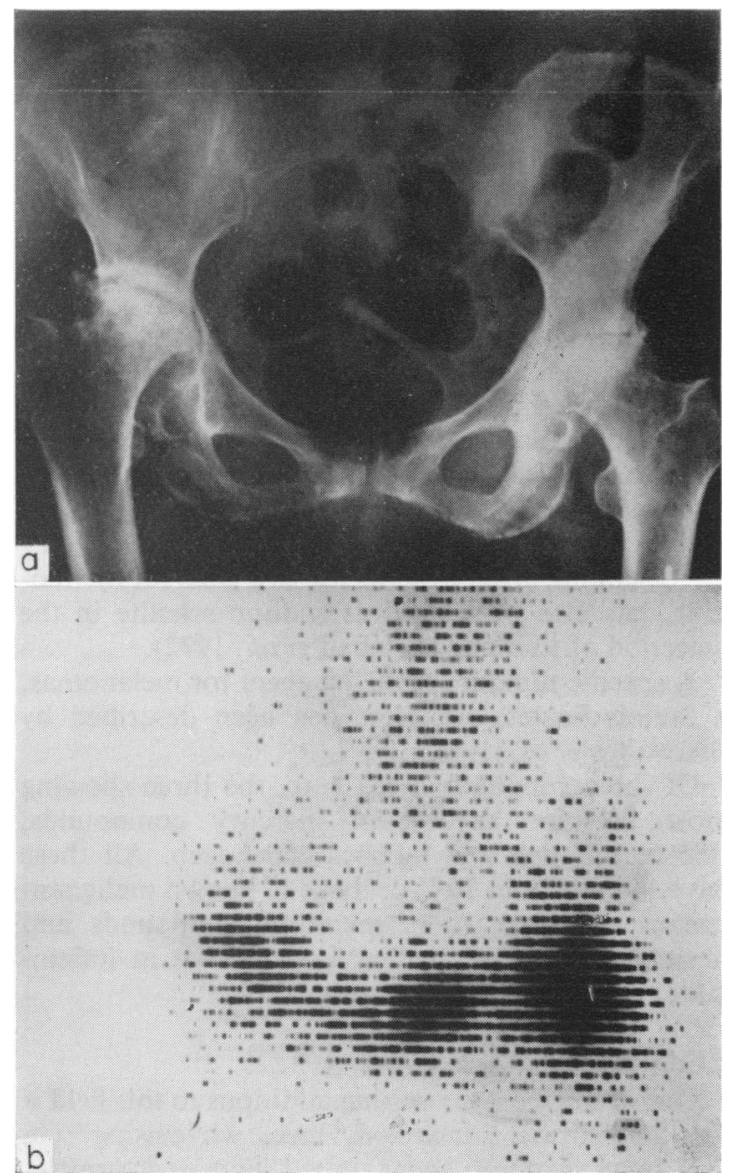

FIG. 16. Positive bone scan, in degenerative arthritis. (a) The view of the pelvis shows marked sclerotic changes in both hips with loss of joint space. (b) The bone scan shows increased radioactivity over both hips. The central area represents radioactivity in the bladder. 


\section{Tumour scanning}

Since the early days of radioisotope scanning there has been a search for a specific radiopharmaceutical which would localize in neoplastic tissue, and considerable research efforts have been made and still continue, exploring various compounds.

Tritiated thymidine and ${ }^{32} \mathrm{P}$ radioactive phosphorus are both incorporated in actively growing cell groups, but cannot be detected externally.

${ }^{75}$ Se-labelled methionine is also metabolized by cells and this factor has been utilized to detect lymphomas (Herrera et al., 1965).

Matthews \& Molinaro (1963) assayed a large number of different compounds in relation to their tumour localization and found that niobium, bismuth and iodinated human serum albumen all achieved relatively high tumour levels. Iodinated human serum albumen has been widely used as a brain scanning agent, but also used to localize other tumours in man (Bonte, Curry \& Oelze, 1966). Neither bismuth nor niobium has been used clinically.

Fibrinogen is known to be present in experimental tumours (Day, Planisek \& Pressman, 1959) and this has been used for the localization of malignant tumours in man (Monasterio, 1964).

The known property of fluorescence of tetracycline in malignant tumours has been explored (Eskelson et al., 1963), and a labelled form of the synthetic vitamin K "Synkavit" has also been used both on experimental tumours and on a small group of patients (Marrian et al., 1969). Radioactive mercury in the form of chlormerodrin was used by Sodee, Renner \& Distefano (1965) on a variety of human new growths.

${ }^{75}$ Selenium, apart from its use as a label for methionine, has also been used as sodium selenite in the detection of tumours (Esteban et al., 1972).

A specific tumour localizing agent for melanomas, a radioiodinated quinoline has been described by Bierwaltes et al. (1968).

Of the compounds listed here, the three showing most promise have been mercury compounds, ${ }^{75} \mathrm{Se}$ methionine and labelled fibrinogen. All these have shown about $70 \%$ or more of known malignant masses. In the case of mercuric compounds and fibrinogen, localization has been shown in inflammatory masses.

\section{${ }^{67}$ Gallium}

One of the most interesting additions to this field is ${ }^{67}$ gallium citrate. Edwards \& Hayes, while using ${ }^{67} \mathrm{Ga}$ as a bone scanning agent, noted increased localisation in malignant nodes in the neck, and in 1970 they reviewed forty-one patients, twenty-three of whom showed positive scans in neoplastic tissue.

Since then a number of papers have appeared reporting localization of gallium in malignant tissue
(Winchell et al., 1970; Langhammer et al., 1972).气 Lavender et al. (1971) pointed out that ${ }^{67}$ galliumz citrate also showed localization in inflammatory lesions, an observation since confirmed by others. $c$

From the reports the total number of positive $\Rightarrow$ scans is $68 \%$, but this success rate varies consider- $-\frac{5}{9}$ ably with different tumours. Thus carcinoma of the lung can be shown in more than $90 \%$ of patients (Fig. 17) but is liable to confusion with inflammatory? lesions.

Lymphomas also show a fairly high success rate (Kay \& McCready, 1972) but primary carcinoma of $\overrightarrow{0}$ the breast and carcinoma of the stomach, for: example, is less successful.

${ }^{67}$ Gallium has also been used to try to make liver scanning more specific. Lomas et al. (1972) report thato in twenty-two patients from a group of twenty-seven:with malignant involvement of the liver there was $\overrightarrow{0}$ increased concentration of gallium compared to 07 surrounding liver parenchyma (Fig. 18).

The clinical applications of gallium therefore are $\vec{P}$ uncertain. It undoubtedly indicates a high proportion of bronchogenic carcinomas but adds little new information. In lymphomas it may well have a real ${ }_{C}$ place in indicating mediastinal involvement, but in all applications there are two objections to its use:firstly the uneven and unpredictable distribution 8 any single patient, and secondly its liability 40 accumulate in inflammatory lesions and therefere produce false positive results.

111 Indium chloride and other recent tumour-seeking $\frac{{ }_{0}^{\circ}}{\circ}$
agents

Because of the chemical affinities between gallium $\overrightarrow{\bar{O}}$ and indium, ${ }^{111}$ indium which, like ${ }^{67}$ gallium has a fairly long half-life, has been put forward as a tumour localizing agent (Hunter \& Riccobone, 1970; Goodwin, Goode \& Brown, 1971).

Our own experience using ${ }^{111}$ indium chloride on $a^{3}$ small group of thirty patients with tumours showed 3 . poor success rate (Merrick et al., 1972), only $22 \%$ showing positive scans.

A completely different principle in tumour localiz-o ing agents is the use of a labelled cytotoxic agent. Nouel et al. (1972) reported on the use of bleomycin, ao cytotoxic agent derived from cultures of streptomyces, labelled with ${ }^{57}$ cobalt on ten patients with ${ }^{\circ}$ cancer, in all of whom positive scans were obtained. $N$ In two of these patients previously unidentified N metastases were shown. Other reports on labelled $\sigma$ bleomycin come from Japan (Kono \& Kojima, 1972; Maeda, Kono \& Kojima, 1972).

Since ${ }^{57}$ cobalt is an unsuitable isotope for clinical $\stackrel{\oplus}{\rightleftharpoons}$ use, an alternative labelling with ${ }^{111}$ indium has been 0 tried both on experimental tumours and in a smallo group of patients suffering from neoplasms. The 

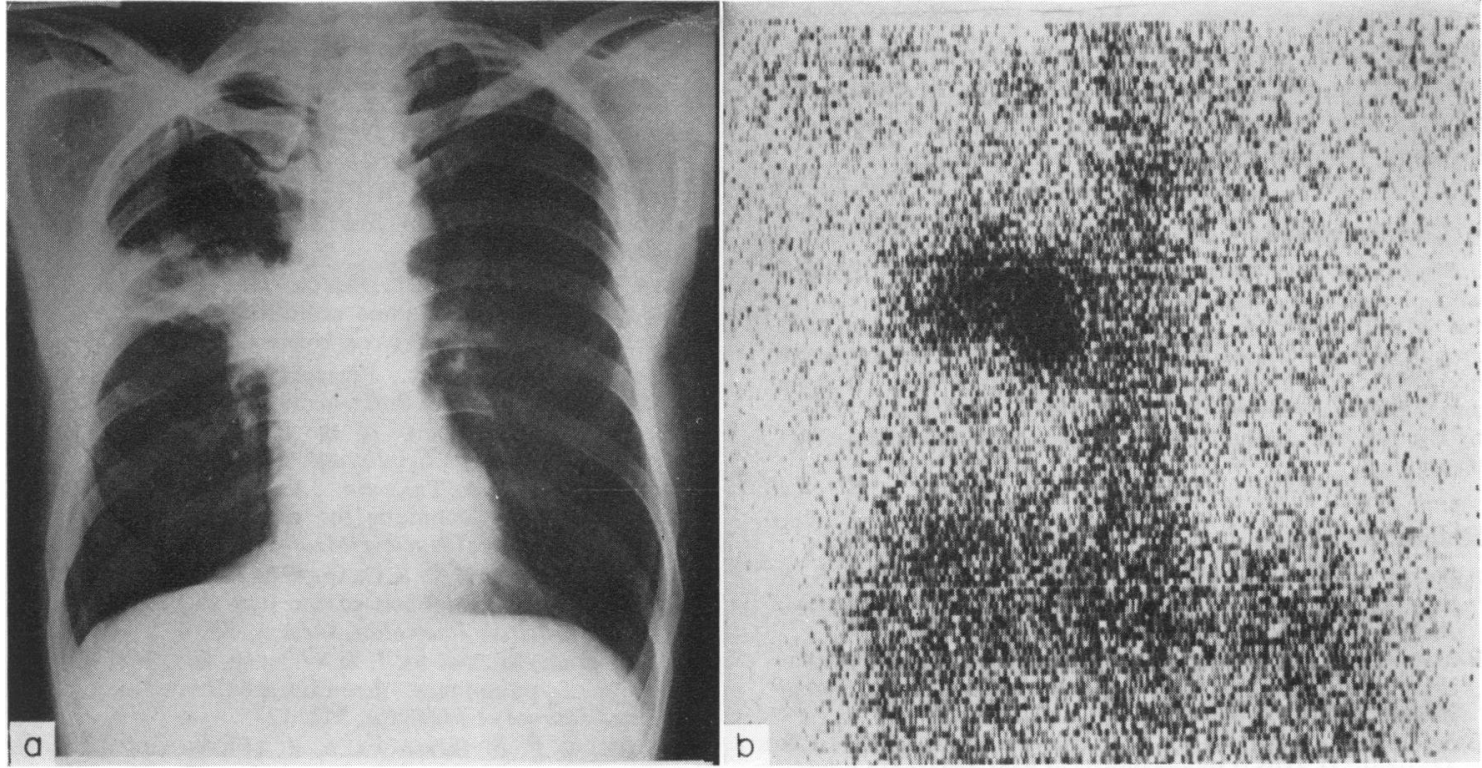

Fig. 17. ${ }^{67}$ Gallium citrate scan on carcinoma of bronchus. (a) Chest X-ray and (b) scan on patient with squamous cell carcinoma of right upper lobe.
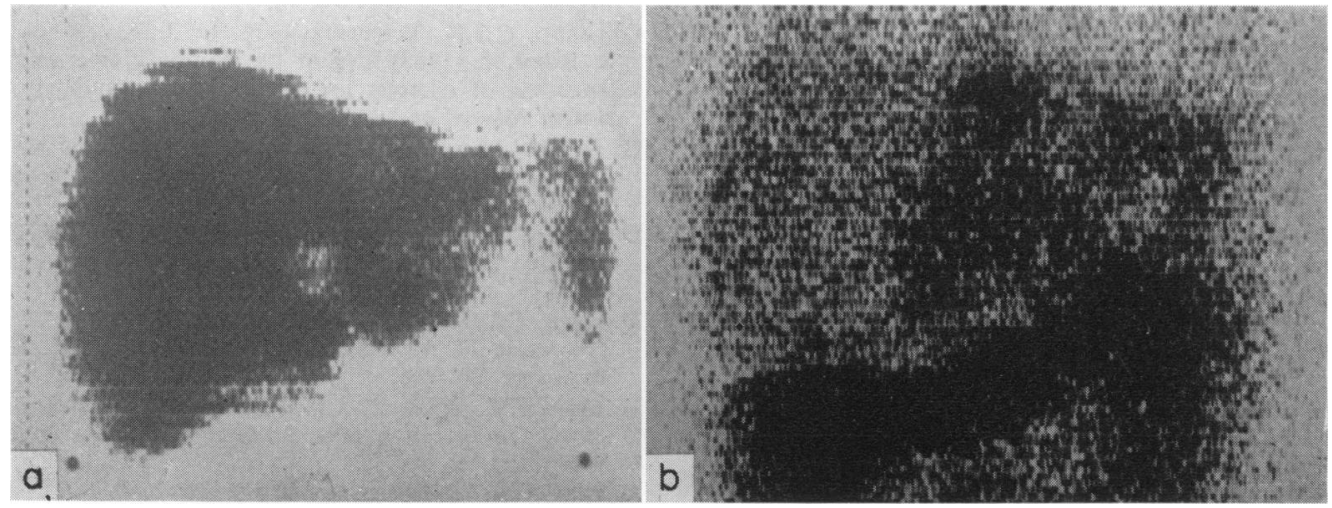

FIG. 18. Colloid liver scan and ${ }^{67}$ gallium citrate scan of liver metastases. (a) On the left is colloid liver scan showing 'cold' areas in the left lobe of the liver of patient with epigastric pain and weight loss. (b) On the right is ${ }^{67} \mathrm{Ga}$ showing isotope in transverse colon and also increased activity in the left lobe of the liver. Metastases from carcinoma of pancreas shown at surgery.

results as reported by Merrick et al. (1972) have been quite encouraging.

\section{Conclusion}

There is a tendency for the techniques of radioisotope scanning to lose credibility due to the rapidly changing techniques. This should not obscure the fact that well established procedures such as brain scanning are of considerable value to patient and clinician. The impending advances in bone scanning with the use of technetium-labelled compounds will, I think, rapidly expand the use of this procedure and make it available as a screening procedure of wide application.

Both liver scanning and lung scanning have a very real contribution in clinical management but must be read carefully in their clinical context.

'Tumour' scanning has always excited interest and 
recent advances seem to justify the efforts made. Even if such a technique is not wholly specific it may still be of value, either in showing the exact size of a known lesion or the total extent of disease. It looks as though this goal may be achieved.

\section{Acknowledgments}

My thanks are due to the Department of Medical Physics who prepare the majority of radiopharmaceuticals; also to the MRC Cyclotron Unit who have supplied cyclotron manufactured isotopes. Lastly I should like to acknowledge my debt to the staff of the Scanning Unit for their patience and high quality work. This work has been supported in part by the Medical Research Council and the Cancer Research Campaign.

\section{References}

Arkles, L.B., Andrews, J.T. \& Steven L.W. (1972) A reappraisal of the scan diagnosis of subdural hematomas. American Journal of Roentgenology, 115, 62.

Baum, S. \& Rothballer, A.B. (1972) The site of accumulation of ${ }^{\circ 9 \mathrm{~m}} \mathrm{Tc}$ in a human brain tumour. American Journal of Roentgenology, 114, 781.

Benacerraf, B., Biozzi, G., Halpern, B.N., Stiffen, C. \& Mouton, D. (1957) Phagocytosis of heat denatured human serum albumin labelled with ${ }^{131} \mathrm{I}$ and its use as a means of investigations with blood flow. British Journal of Experimental Pathology, 38, 35.

Bierwaltes, W.H., Varma, V.M., Lieberman, L.M., Counsell, R.E. \& Morales, J.O. (1968) Scintillation scanning of malignant melanomas with radio-iodinated quinoline derivatives. Journal of Laboratory and Clinical Medicine, 72, 485.

BlaU, M. \& Bender, M.A. (1959) Radiomercury $\left({ }^{208} \mathrm{Hg}\right)$ labelled neohydrin; a new agent for brain tumour localization. Journal of Nuclear Medicine (Convention issue), p. 35.

Bonte, F.J., Curry, T.S., \& Oelze, T.E. (1966) Tumor scanning with intravenous ${ }^{131}$ I H.S.A. Radiology, 86, 742.

BuCY, P.C. \& CiRIC, I.S. (1965) Brain scans in the diagnosis of brain tumours. Journal of the American Medical Association, $191,437$.

Bull, J.W.D. \& ZiRKhA, K.J. (1968) Rationalizing requests for X-ray films in neurology. British Medical Journal, 4, 569.

Charkes, N.D., Sklaroff, D.M. \& Young, I. (1966) A critical analysis of strontium bone scanning for detection of metastatic cancer. American Journal of Roentgenology, 96, 647.

Chaudhuri, T.K., Schapiro, R.L. \& Christie, J.H. (1972) Positive ${ }^{87} \mathrm{Sr}$ bone scan in a case of hypertrophic pulmonary osteoarthropathy. Journal of Nuclear Medicine, 13, 120.

Cuzer, E.E. \& IoANNides, G. (1971) Brain scanning in herpes simplex encephalitis. American Journal of Roentgenology, 112, 273.

Day, E.D., Planisek, J.A. \& Pressman, D. (1959) Localization of radio-iodinated rat fibrinogen in transplanted rat tumours. Journal of the National Cancer Institute, 23, 799.

De NARDo, G.L. (1966) The ${ }^{85} \mathrm{Sr}$ strontium in bone disease. Annals of Internal Medicine, 65, 44.

DollerY, C.T. \& WEST, J.B. (1960) Regional uptake of radioactive oxygen. Carbon monoxide and carbon dioxide in the lungs of patients with mitral stenosis. Circulation Research, 8, 765.

Dudley, N.C. \& Maddox, G.E. (1949) Deposition of radiogallium $\left({ }^{i 2} \mathrm{Ga}\right)$ in skeletal tissues. Journal of Pharmacology and Experimental Therapeutics, 96, 224.
Eddleston, A.L.W.F., Rake, M.O., Pagalsos, A.P., Osborñ S.B. \& Williams, R. (1972) ${ }^{75}$ Se selenomethionine in the scintiscan diagnosis of primary hepato-cellular carcinomad Gut, 12, 245.

EDWARDS, C.L. \& HaYES, R.L. (1969) Tumour scanning with: ${ }^{67} \mathrm{Ga}$ citrate. Journal of Nuclear Medicine, 10, 103.

EDWARDS, C.L. \& HAYES, R.L. (1970) Scanning malignan $\mathrm{t}^{+}$ neoplasms with ${ }^{67}$ gallium. Journal of the American Medicat Association, 212, 1182.

Eskelson, C.D., DunN, A.L., Osborn, R.E. \& McLeaY, J.F $\frac{\bar{s}}{9}$ (1963) Distribution of some radio-iodinated tetracycline 8 in animals. Journal of Nuclear Medicine, 4, 382.

Esteban, J., Vazquez, R., Fombellida, J.C., Caballerớ, O. \& Llobis, A. (1972) Positive diagnosis of tumours wit ${ }^{75}$ Se selenite. Proceedings of the I.A.E.A. Symposium on. Medical Radioisotope Scintigraphy, October, 1972.

Farmelant, M.H. \& Trainor, J.C. (1971) Evaluation of ${ }^{133} \mathrm{Xe}$ ventilation technique for diagnosis of pulmonary disorders. Journal of Nuclear Medicine, 12, 586.

Flanc, C., KaKkar, V.V. \& Clarke, M.B. (1968) The detection of venous thrombosis of the legs using ${ }^{125}$ I labelle $b \vec{b}$ fibrinogen. British Journal of Surgery, 55, 742.

Freiman, D.G., Suzemoto, J. \& Wessler, S. (1965) The fre quency of pulmonary thromboemboli in man. Nen England Journal of Medicine, 272, 1278.

Friedman, W.F. \& Braunwald, E. (1966) Alterations ib regional pulmcnary blood flow in mitral valve disease studied by radioisotope scanning. Circulation, 34, 363.

French, R.J. \& MCCready, V.R. (1967) The use of ${ }^{18} \mathrm{~F}$ fo bone scanning. British Journal of Radiology, 40, 655.

Galasko, C.S.B. (1969) The detection of skeletal metastases from mammary cancer by gamma camera scintigrapon British Journal of Surgery, 56, 757.

Galasko, C.S.B., Westerman, B., Li, J., Sellwood, RনA \& BURN, I. (1968) Use of the gamma camera for eqlo detection of osseous metastasis from mammary cancep British Journal of Surgery, 55, 613.

Glasgow, J.L., Currier, R.D. \& Goodrich, J.K. (1961 Brain scans of cerebral infarcts with radioactive mercury Radiology, 88, 1086.

GoodwIN, D.A., Goode, R. \& BRown, L. (1971) ${ }^{111} \overline{\overline{\bar{\Phi}}}$ labelled transferrin for the detection of tumours. Radiolog $100,175$.

Harmer, C.L., Burns, J.E., Sams, A. \& Spittle, A. (1969 The value of for ${ }^{18} \mathrm{~F}$ scanning bone tumours. Clinicait Radiology, 20, 204.

HaRPER, P.V., Beck, R., Charleston, D. \& Lathrop, K.A (1964) Optimization of a scanning method using ${ }^{90 \mathrm{~m} T} \mathrm{~T}$ Nucleonics, 22, 50.

Herrera, N.E., Gonzales, T., Schwartz, R.D., Digg凫 A.M., \& BeLsKY, J. (1965) ${ }^{75}$ Se methionine as a diagnostie agent in malignant lymphoma. Journal of Nuclear Medicine 6, 792.

HunteR, W.W. \& Riccobono, X.J. (1970) Clinical evaluatio of ${ }^{111}$ In for localization of recognized neoplastic disease. Journal of Nuclear Medicine, 11, 328.

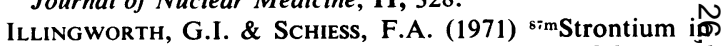
prognosis of fractures of the tibia. Proceedings of the Royat Society of Medicine, 64, 633.

JoRdAN, C.E., JAMEs, A.A. \& Hodges, F.J. (1972) Comparisoßv of the cerebral angiogram and the brain radionuclide image in brain abscess. Radiology, 104, 327.

KAY, D.N. \& McCready, V.R. (1972) Clinical isotop scanning using ${ }^{67} \mathrm{Ga}$ citrate in the management of Hodgkin disease. British Journal of Radiology, 45, 437.

Kuhl, D. E. \& SANDERS, T. P. (1971) Characterizing brain lesions with use of transverse section scanning. Radiolog 98, 317 . 
Knipping, H.W., Bolt, W., Valentin, H., Venrath, H. \& ENDLER, P. (1955) Eine neve methode zur prüfung der herz und lungenfunktion; die regionale funktionsanalyse in der lungen und herzklinik mit hilfe des radioaktiven edelyases Xenon 133. Deutsches Medizine Wochenschrift, 80, 1146.

Kono, A., \& KoJima, M. (1972) The tumor specific localizing agents for radioisotope image. Radioisotopes, 21, 64.

Krishnamurthy, C.T., Walsh, C., Winston, M.A., Weiss, G.R. \& BLAND, W.H. (1972) Comparison of ${ }^{18} \mathrm{~F}$ bone studies obtained with rectilinear scanner and scintillation camera equipped with high energy diverging hole collimator. Radiology, 103, 365.

Kuba, J., Klaus, E. \& Sevcik, M. (1971) Comparison of scintigraphy and angiography in the diagnosis of intracranial space occupying lesions. Nuclear Medizin, 10, 105.

Langhammer, H., Glaubitt, D., Grebe, S.F., Hampe, J.F., Haubold, A., Hor, G., Kaul, A., Koeppe, P., KoppemHagen, J. Roedler, H.D. \& VAN DER SchoOt, J.B. (1972) ${ }^{67} \mathrm{Ga}$ for tumour scanning. Journal of Nuclear Medicine, 13, 25.

LAVENDER, J.P., LoWe, J., BARKer, J.T., BURN, J.I. \& Chaudhri, M.A. (1971) Gallium 67 citrate scanning in neoplastic and inflammatory lesions. British Journal of Radiology, 44, 361.

Lomas, E., McKusick, K.A., Dibos, P.E., \& Wagner, H.N. (1972) Ionic ${ }^{67} \mathrm{Ga}$ and ${ }^{111} \mathrm{In}$ in the differential diagnosis of focal liver disease. Journal of Nuclear Medicine, 13, 450.

MaEdA, T., Kono, A. \& KoJima, M. (1972) Tumor scanning with ${ }^{57}$ Co bleomycin Radioisotopes, $21,56$.

MCAFEe, J.G., AuSE, R.G. \& W AGNER, H.N. (1965) Diagnostic value of scintillation scanning of the liver. Archives of Internal Medicine, 116, 95.

MCAfee, J.G., Fueger, E.F., Stern, H.S., WAgner, H.N. \& MigitA, T. (1964) ${ }^{\circ 9 m}$ Tc pertechnetate for brain scanning. Journal of Nuclear Medicine, 5, 811.

McIntyre, A.M. \& Sasahara, A.A. (1971) Correlation of pulmonary photoscan and angiogram as measures of the severity of pulmonary embolic involvement. Journal of Nuclear Medicine, 12, 723.

Mclaughlin, A.F., Crocker, E.F. \& Morris, J.G. (1972) Brain scanning in intracranial infection. Journal of Nuclear Medicine, 13, 451.

MarRian, D.H. Mitchell, J.S., Bull, C.H., King, G.A. \& SzAZ, K.F. (1969) Labelled compound related to synkavit and its uptake in certain tumours studied by radioisotope scanning. Acta radiologica, 8, 221.

Matthews, C.M.E. \& Molinaro, G. (1963) A study of the relative value of radioactive substances used for brain tumour localization and of the mechanism of tumour; brain concentration uptake in transplantable fibrosarcoma, brain and other organs in the rat. British Journal of Experimental Pathology, 44, 260.

Medina, J.R., Lilihei, J.P., Loken, M.K .\& Ebert, R.F. (1969) Use of the scintillation anger camera and ${ }^{138}$ xenon in the study of chronic obstructive lung disease. Journal of the American Medical Association, 208, 985.

MerricK, M.V. (1973) Detection of skeletal secondary deposits: a comparison of three isotopic techniques and radiology. British Journal of Radiology (In press).

Merrick, M.V., Gunasekera, S.W., LAVENDER, J.P., NunN, A.D., Thakur, M.L. \& Williams, E.D. (1972) The use of "11indium for tumour localization. A comparison of several chelates with "gallium in inflammatory and neoplastic lesions, with a note on indium-labelled bleomycin. Proceedings of the I.A.E.E. Symposium on Medical Radioisotope Scintigraphy. October, 1972.

Molinari, G. F., Percher, F. \& Heyman, A. (1967) Serial brain scanning using ${ }^{89 \mathrm{~m}} \mathrm{Tc}$ in patients with cerebral infarction. Neurology, 17, 627.
Monasterio, G. (1964) Radioactive fibrinogen for the diagnosis of tumours. Bologna Society of Internal Surgery, 23, 233.

Moody, R.A., Olsen, J.O., Gottschalk, A. \& Hoffer, P.B. (1972) Brain scans of the posterior fossa. Journal of Neurosurgery, 36, 148.

Moore, G.F. (1948) The use of radioactive di-iodo-fluorescein in diagnosis and localization of brain tumours. Science, $107,569$.

Morrison, R.T., Afifi, A.K., Van Allen, M.W. \& Evans, T.C. (1965) Scintiencephalography for detection and localization of non-neoplastic intracranial lesions. Journal of Nuclear Medicine, 6, 7.

Moses, D.C., James, E., Strauss, H.W. \& Wagner, H.N. (1972) Regional cerebral blood flow estimation in the diagnosis of cerebrovascular disease. Journal of Nuclear Medicine, 13, 135.

Muheim, G., \& CRutchlow, W.P. (1971) ${ }^{18} \mathrm{~F}$ and ${ }^{85} \mathrm{Sr}$ scintemetry in the study of primary arthriopathics. British Journal of Radiology, 44, 240.

Nagler, W., Bender, M.A., \& BlaU, M. (1963) Radioisotope photoscanning of the liver. Gastroenterology, 44, 36.

Naoun, R.J., Picard, L., Montout, J. \& Bertrand, A. (1971) La scintigraphie cranieux a l'aide du technetium $99^{\mathrm{m}}$ a propos de 1100 observations. Annalles de Radiologie, 14, 575.

NATHAN, B.E. (1972) Unpublished data.

Nouel, J.P., Renault, H., Robert, J., Jeanne, C. \& Wicent, L. (1972) La Nouvelle Pressé Medicale, 1, 95.

Overton, M.E., HaYnie, T.P. \& SNOdgrass, S.R. (1965) Brain scans in non-neoplastic intracranial lesions scanning with chlormerodrin ${ }^{203} \mathrm{Hg}$ and chlormerodrin ${ }^{10} \mathrm{Hg}$. Journal of the American Medical Association, 191, 431.

Pecher, C. (1942) Biological investigations with radioactive calcium and strontium. University of California Publications in Pharmacology. 2, 117.

PophaM, M.G. (1972) Numerical methods for the detection of abnormalities in radionuclide brain scans. In: Progress in Nuclear Medicine, Vol. 1, p. 115. S. Karger, Basel.

Powell, M. \& Mangum, J. (1972) Diagnostic efficiency of liver scintiphotography. Hematopoietic and Gastrointestinal Investigations with Radionuclides, p. 415. C. C. Thomas, Springfield, Ill.

Rollo, F.D., \& DELAND, F.H. (1968) The determination of liver mass from radionuclide images. Radiology, 91, 1191.

Ronai, P., Winchell, H.G. \& ANGer, H.L. (1968) Skeletal survey for metastatic tumours of bone using ${ }^{18} \mathrm{~F}$ and ${ }^{85} \mathrm{Sr}$ with scintillation camera and whole body scanner. Journal of Nuclear Medicine, 9, 520.

ROSENTHALL, L. (1971) Intravenous and intracarotid radionuclide angiography. Seminars in Nuclear Medicine, 1, 70.

Roy, R.R., NAThan, B.E., BeAles, J.S.M.\& Chisholm, G.D. (1971) 18 Fluorine total body scans in patients with carcinoma of the prostate. British Journal of Urology, 43, 58.

Rywlin, A. (1970) Pulmonary Investigation with Radionuclides, p. 329. C. C. Thomas, Springfield, Ill.

SauerbrunN, B.J.L., Hansen, H., Napoli, L. \& Hill, O. (1972) Strontium bone scans in Ca lung. A comparative prospective study. Journal of Nuclear Medicine, 13, 465.

SchwarTz, M.L. \& TATOR, C.H. (1972) Shortcomings of ${ }^{\circ \mathrm{m}} \mathrm{Tc}$ pertechnetate as a tracer for brain tumour detection as shown by human brain tumours and a mouse ependymoblastoma. Journal of Nuclear Medicine, 13, 321.

Secker Walker, R.H., Jackson, J.A. \& Goodwin, J. (1970) The resolution of pulmonary emboli. British Medical Journal, 4, 125.

Shaldon, S., Ohiandussi, L., Guervara, L., Caesar, J. \& SHERLOCK, S. (1961) The estimation of hepatic blood flow and intrahepatic blood flow and intrahepatic shunted 
blood flow by colloidal heat denatured human serum albumen labelled with ${ }^{13}$ I. Journal of Clinical Investigation, 40, 1346.

Sodee, D.B., Renner, R.R. \& Distefano, B. (1965) Photoscanning localization of tumors utilizing chlormerodrin mercury 197. Radiology, 84, 873.

Spencer, R.P., Lange, R.C. \& Treves, G. (1971) Use of ${ }^{135 \mathrm{~m}} \mathrm{Ba}$ and ${ }^{181} \mathrm{Ba}$ as bone scanning agents. Journal of Nuclear Medicine 12, 216.

StirretT, L.A., Yuhl, E.T. \& Cassen, B. (1954) Clinical applications of hepatic radioactive surveys. American Journal of Gastroenterology, 21, 310.

Subramanian, G. \& McAfee, J.G. (1971) A new complex of ${ }^{99 \mathrm{~m} T c}$ for skeletal imaging. Radiology, 99, 192.

Subramanian, G., McAfee, J.G., Blair, R.J., O'Mara, R.E., GreEN, M.W. \& Lebowitz, E. (1971a) ${ }^{157}$ Dy HEDTA for skeletal imaging. Journal of Nuclear Medicine, 12, 558.

Subramanian, G., McAfee, J.G., O'Mara, R.E., RosenSTREICH, M. \& MeHTER, A. (1971b) ${ }^{98 \mathrm{~m} T c}$ polyphosphate p.p. 46: a new radiopharmaceutical for skeletal imaging. Journal of Nuclear Medicine, 12, 399.

Taplin, G.V., Johnson, D.E., Dore, E.K. \& KaPlan, H.S. (1964) Lung photo-scans with macroaggregates of human serum radio-albumin. Experimental basis and initial clinical trials. Health Physics, 10, 1219.

TaPlin, G.V., Meredith, O.M. \& KADE, H. (1965) The radioactive ${ }^{131} \mathrm{I}$ tagged Rose Bengal uptake excretion test for liver function using gamma ray scintillation counting techniques. Journal of Laboratory and Clinical Medicine, 45, 665 .

TAPlin, G.V. \& PoE, N.D. (1965) A dual lung scanning technique for evaluation of pulmonary function. Radiology, $85,364$.

Tow, D.E. \& WAGNER, H.N. (1966) The recovery of pulmonary arterial blood flow in patients with pulmonary embolism. New England Journal of Medicine, 276, 1053.
Tow, D.E. \& WAGNER, H.N. (1967) Scanning for tumours ैㅜㅇ brain and bone. Journal of the American Medical Associa tion, 199, 104.

Vaughan, R.J., Lovergrove, F.T.A., Fleary, R.F. \& QUINLAH, M.F. (1971) Scintiscanning in the detection and diagnosis of subdural hematoma and hygroma. Australia两 and New Zealand Journal of Surgery, 40, 343.

VIDRIH, V.E. \& Higgins, H.P. (1971) Accuracy of live scintiphotography using a plastic and water phantore Canadian Journal of Surgery, 14, 273.

WAGner, H.N., Sabiston, D.C., Ito, M., McAfee, J.C.

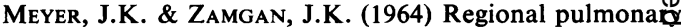
blood flow in man by radioisotope scanning. Journæl of the American Medical Association, 187, 601.

Webber, M.M., Resnie, L.H., FouAd, B. \& Victery, W. (1972) Variants of the normal lung scan: correlation with pulmonary function tests. Journal of Nuclear Medicine, 13 476.

WEST, J.B. (1960) Distribution of blood flow and ventilatiogs perfusion ratio in the lung measured with radioactive $\mathrm{CO}$ Journal of Applied Physiology, 15, 405.

Wilson, A.G., Harris, C.N., Lavender, J.P. \& OAKle C.M. (1973) Perfusion lung scanning in obliterative pub monary hypertension. British Heart Journal. (In press)

Winchell, H.S., Sanchez, P.D., Watanabe, C.K., Hol lander, L., ANger, H.O., McRae, J., Hayes, R.L. \& EDWARDS, C.L. (1970) Visualization of tumours in humang using ${ }^{67} \mathrm{Ga}$ citrate and the Anger whole-body scanne scintillation camera and tomographic scanner. Journal of Nuclear Medicine, 11, 459.

Wise, G., Brockenbrough, E.C., Marti, R. \& Griep, (1971) Detection of carotid artery obstruction correlated with arteriography. Stroke, 2, 105.

Yano, Y., MCRAe, J., VAN DYKe, D.C. \& ANGer, (1972) ${ }^{90 \mathrm{~m} T c}$ labelled SN-Diphosphonate: a bone ing agent. Journal of Nuclear Medicine, 13, 480. 